\title{
Bioprinting for Vascular and Vascularized Tissue Biofabrication
}

\author{
Pallab Datta ${ }^{1}$, Bugra Ayan ${ }^{2,3}$, Ibrahim T. Ozbolat ${ }^{2,3,4,5}$ \\ ${ }^{1}$ Centre for Healthcare Science and Technology, Indian Institute of Engineering Science and Technology Shibpur, \\ Howrah, 711103, West Bengal, India \\ ${ }^{2}$ Engineering Science and Mechanics Department, Penn State University, University Park, PA, 16802, USA \\ ${ }^{3}$ The Huck Institutes of the Life Sciences, Penn State University, University Park, PA, 16802, USA \\ ${ }^{4}$ Biomedical Engineering Department, Penn State University, University Park, PA, 16802, USA \\ ${ }^{5}$ Materials Research Institute, Penn State University, University Park, PA, 16802, USA
}

\begin{abstract}
Bioprinting is a promising technology to fabricate design-specific tissue constructs due to its ability to create complex, heterocellular structures with anatomical precision. Bioprinting enables the deposition of various biologics including growth factors, cells, genes, neo-tissues and extra-cellular matrix-like hydrogels. Benefits of bioprinting have started to make a mark in the fields of tissue engineering, regenerative medicine and pharmaceutics. Specifically, in the field of tissue engineering, the creation of vascularized tissue constructs has remained a principal challenge till date. However, given the myriad advantages over other biofabrication methods, it becomes organic to expect that bioprinting can provide a viable solution for the vascularization problem, and facilitate the clinical translation of tissue engineered constructs. This article provides a comprehensive account of bioprinting of vascular and vascularized tissue constructs. The review is structured as introducing the scope of bioprinting in tissue engineering applications, key vascular anatomical features and then a thorough coverage of 3D bioprinting using extrusion-, droplet- and laser-based bioprinting for fabrication of vascular tissue constructs. The review then provides the reader with the use of bioprinting for obtaining thick vascularized tissues using sacrificial bioink materials. Current challenges are discussed, a comparative evaluation of different bioprinting modalities is presented and future prospects are provided to the reader.
\end{abstract}

Keywords: 3D bioprinting, microvascular network, small diameter blood vessels, vascularized thick tissues, extrusion-based bioprinting, droplet-based bioprinting, laser-based bioprinting 


\section{Introduction}

Three-dimensional (3D) printing technology has witnessed rapid strides from being considered a futuristic technology, as it promises to revolutionize clinical practice by making available customized equipment, organ models for surgical practices, organ replacement parts, and drugs, at a pace not witnessed before [1-5]. Though initially this technology was envisioned to provide surgical models and prototypes, scientists have quickly advanced the technology to produce tissue constructs for regenerative medicine; however, large-scale adaptation has still been limited due to the anatomical complexity and compositional (cellular and extracellular) diversity, and vascularization of native tissues [6]. In this respect, though significant advances have been made to recreate the geometric complexity, the concern of developing vascularization within tissue constructs still haunts scientists as the holy grail of tissue engineering [7,8]. In this context, bioprinting emerges as a promising method for fabrication of vascular constructs and vascularized tissues, general concept of which is described schematically in Figure 1 and through the paper.

\subsection{Bioprinting}

Bioprinting can be defined as the spatial patterning of living cells and other biologics by stacking and assembling them using a computer-aided layer-by-layer deposition approach for fabrication of living tissue and organ analogs for tissue engineering, regenerative medicine, pharmacokinetic, cancer research [9] and other biological studies [10]. With the emergence of bioprinting in medical and pharmaceutical research [11], the substantial evolution in bioprinter designs have also taken place with successful commercialization of several bioprinters, a comprehensive review on which has been presented recently [12]. Briefly, according to their working mechanism, bioprinting technologies can be classified into three major modalities including extrusion-based bioprinting (EBB), droplet-based bioprinting (DBB) and laser-based bioprinting (LBB) [10,13], many of which have been used for vascular or vascularized tissue fabrication. However, before examining the potential of bioprinting to create artificial blood vessels, a brief account of the anatomy of blood vessels are presented to define the target tissue of bioprinting. 


\subsection{Anatomy of vascular tissue}

The structure of blood vessels is characterized by a concentric layer arrangement; with cellular and non-cellular composition of each layer showing distinct variations (see Fig.1). The intima, or the innermost layer, contains a monolayer of endothelial cells (ECs) and forms a tight barrier between the vessel lumen and vessel wall. This layer provides non-thrombogenicity and resistance to infections. The basement membrane forms the next layer and is composed of Type IV collagen and laminin. This layer is followed by elastin layer, also known as internal elastic lamina [14]. After intimal layer, the medial layer is composed of Type I and III collagen, along with smooth muscle cells (SMCs). These cells possess coordinated contractile properties, which cause vessel contraction or dilation [15]. Herein, collagen fibers and SMCs are in spiral arrangement along the vessel axis. The medial layer is quite thickened in large arteries and may also contain nervous supply. Further, the medial layer is circumvented by external elastic lamina. The outermost layer is the adventitia, which is composed of fibroblasts rooted on a loose collagen matrix. These layers continually interact with each other in remodeling and perfusion of organs they supply [16]. It is worthwhile to note that while larger vasculature can be identified as separate anatomical entities, micro-vessels are structurally and functionally part of the tissue they supply. The microvasculature is composed of three types of vessels namely arterioles, capillaries, and venules, which form a network architecture. The arteries branch down to arterioles, which are typically 10-200 $\mu \mathrm{m}$ in diameter (average lumen diameter being $30 \mu \mathrm{m}$ ) composed of the three tunic layers as found in macro-vessels, but with reduction in thickness of these layers. The endothelial lining of tunica intima is intact, while in tunica media, only to one or two smooth muscle cell layers are found. The tunica externa also becomes thinner compared to arteries. The arterioles are richly innervated by sympathetic nerves, because of which they can control of blood volume or pressure. The arterioles continue into the capillaries, and the connecting arterioles are referred to as meta-arterioles. Metarterioles act as precapillary sphincters and lack the true tunica media structures, wherein a single smooth muscle cell encircles the metarteriolecapillary. Capillaries are the part of microscopic vessels with lumen diameter of approximately 5-10 $\mu \mathrm{m}$. In the capillary walls, endothelial layer is surrounded by a basement membrane and generally does not contain any smooth muscle, though pericytes are present to stabilize the wall structure. This structural feature allows reduction in the distance of diffusion for solutes to reach the cells of the tissue. In addition, capillary structure of different tissues may allow different 
solute permeability, and accordingly capillaries are classified as continuous, fenestrated or sinusoid capillaries. Found in muscle, skin, lung, central nervous system, basement membrane is continuous and intercellular clefts between adjacent endothelial cells have tight junctions. The fenestrated capillaries contain porous structures and are seen in exocrine glands, renal glomeruli, and intestinal mucosa while capillaries with large intercellular gaps are observed in liver, spleen and bone marrow. Sinusoidal capillaries are flattened with incomplete basement membranes and large gaps between cells. Capillaries arising out of a single metarteriole reunite and empty into a venule, which is generally $8-100 \mu \mathrm{m}$ in diameter. Such multiple venules join to form veins. The venules walls contain an endothelium, a few muscle cells and elastic fibers in the middle layer, and a thin tunica externa composed of connective tissue fibers [17,18].

\subsection{Need for the vascular tissue towards fabrication of tissues and organs at the clinically-relevant volumes}

Since the last two decades, it has been agreed that it is essential to recreate the hierarchical vascular network which can ensure steady perfusion of implant-injury sites for successful engineering of most complex tissues [19]; however, this issue has persisted as a major limitation over years on generating engineered tissues of clinically-relevant volumes and complexities [20,21]. Apart from providing diffusion and mass transport of nutrients, substantial evidences also suggest that integration of vascular network also plays a pivotal role in governing tissue formation [22,23]. Additionally, micro-vascularized tissue constructs would significantly improve clinical outcome with respect to innervations and complete functional recovery, as indicated by revelation of several cross-talk mechanisms between vascular promoting factors, endothelial cells and nerve cells [24-27]. Except for tissues, such as avascular cartilage or cornea, wherein vascularization may cause inflammatory reactions [28], engineered constructs with thickness of more than a millimeter does not remain viable without vascularization [29]. Currently, tissue constructs of greater than $200 \mu \mathrm{m}$ in thickness (the diffusion limit of oxygen from nearest capillaries under in-vivo conditions) have little chance of subsequent clinical success in most complex tissues [30]. In highly vascularized tissues, such as liver, kidney, lungs, spleen, heart, pancreas, or thyroid, formation of new blood vessels becomes essential for a tissue to grow beyond the diffusion limit $[31,32]$. Since most present tissue engineering strategies are evaluated in much smaller volumes than the requirements of larger clinical reconstruction, successful scaling is essential in order to ensure their clinical applicability. For example, in case 
of liver tissue, there exists a huge demand for tissue construct of clinically-relevant volumes (i.e., about $500 \mathrm{~cm}^{3}$ ) required of implantable liver with the cell density and functionality being close to native liver tissue [33-35].

Vascular tissue fabrication via the tissue engineering route comprises several approaches depending upon the function required. For one, vascular tissues are required for coronary vessel surgeries. Patients suffering from cardiovascular diseases like cerebrovascular disease, coronary heart disease, deep vein thrombosis, and peripheral arterial disease, which are associated with vessel blockages and require long-term (life expectancy >2 years) revascularization are principally indicated for vascular replacements like coronary arterial bypass grafting. However, synthetic vascular grafts have satisfactory results documented only for large-diameter ( $>8 \mathrm{~mm})$ such as aortoiliac or medium-diameter $(6-8 \mathrm{~mm})$ carotid or common femoral artery arteries replacements. Their performance in small-caliber vessels $(<6 \mathrm{~mm})$ like coronary, infrainguinal or infrageniculate arteries reconstruction remains poorer compared to the gold standard autologous grafts harvested from internal thoracic or radial artery, and saphenous vein (SV). Thus the Food and Drugs Administration (FDA) does not approve the synthetic biomaterial based small caliber vascular grafts (internal diameter $<5 \mathrm{~mm}$ ) due to poor patency rates though autologous grafting may not be suitable for a large number of patients due to poor quality of donor site. These failures are usually due to initimal hyperplasia, thrombosis or infections of the graft. Absence of healthy endothelial cell layer, diameter mismatch, synthetic material surface properties and compliance mismatch with the native tissue are contributory factors to all these mechanisms [36,37]. Bioprinting with suitable endothelial cell source into the diameters required is thus an attractive approach to engineer small diameter blood vessels and has been pursued.

Apart from fabrication of vascular grafts, vascularization is also endeavored to be improved for blood circulation by fabrication of a vascular microcirculatory network at affected regions of other tissues, encourage vessel in-growth into implanted constructs from the host, or to generate new circulation system at the local site through stem cell therapy [38]. In human embryos as well as adult tissues, new vascular networks are formed by two distinct mechanisms known as vasculogenesis and angiogenesis. The former refers to de novo generation of blood vessel from vascular progenitor cells or the capillary plexus formation from circulating EPCs while angiogenesis is used to indicate sprouting of new vessels blood vessels via extension or 
remodeling from pre-existing capillaries. The process of angiogenesis can occur through elongation, inosculation, intussusception, or sprouting. Amongst them, intussusception involves bifurcation of existing lumen while sprouting is an outcome of multistep processes involving first the resorption of basement membrane, followed by infiltration and growth of ECs, lumen organization and subsequent formation of vessel with the addition of pericytes. The process of inosculation is important for making connection between the vascular networks transplanted and host microcirculatory network. In the context of tissue engineering, it is observed that EPCs can be expanded ex vivo and transplanted to augment neovascularization for engineering of vascular structures. Further, EPC recruitment can be enhanced by stromal-derived factor-1, and granulocyte colony stimulating factor, amongst others [39-42]. Thus, vasculogenesis-driven mechanism of vascular tissue engineering can be adopted for bioprinting.

Angiogenesis promoting strategies have focused on either in-growth of newly formed capillaries inside implanted constructs from the host or to achieve a rapid blood supply within engineered constructs by stimulating inosculation with the help of pre-vascularized constructs $[29,43]$. After implantation, the pre-vascularized channels within the constructs develop interconnections with neighboring tissue vessel network to get perfused rapidly. In other approaches, angiogenesis promoting agents like vascular endothelial growth factor (VEGF), fibroblast growth factor (FGF), platelet-derived growth factor (PDGF), and transforming growth factor (TGF), either alone or in co-delivery forms are often employed $[44,45]$. The recruitment of circulating stem cells into ischemic sites by targeted activation of concerned pathways or by cell seeding into the constructs are other approaches for achieving vascularization. In this respect, Tasso et al. have reported that mesenchymal stem cells (MSCs) seeded into porous cubes resulted in homing of pericyte-like cells or circulating endothelial progenitor cells (EPC) inside engineered constructs after implantation. However, teratoma formation or tumorogenicity of various cell sources, including stem cells, remains unaddressed for standardization of tissue constructs [46]. Other potential sources for vascular cells are adult bone marrow, adipose tissue, hair follicle (HF), umbilical cord (UC), and muscles. Amongst them, the adipose derived stem cells (ADSC) are shown to differentiate into multiple cell types of vascular tissue including smooth muscle cells on inducted by transforming growth factor-beta 1 (TGF- $\beta 1$ ) or bone morphogenetic protein- 4 (BMP-4) and found to be a rich source of endothelial cells. Provided the fact that adipose tissue is routinely harvested during liposuction procedures, they constitute a promising source for 
vascular tissue engineering. On the other hand, hair follicles and umbilical cords can also be obtained without invasive procedures and the various stem cells isolated from these sources have shown promising differentiation potential into vascular tissue [47]. Further, newer biological understanding indicates that cellular crosstalk is involved in angiogenesis as well as organ remodeling process [48]. An example is the cross-interaction between ECs, osteoblasts, osteoclasts and osteo-progenitors, which aremediated by secretion of soluble factors and gap junction proteins like connexin 43. Though it can be concluded that various cells types have been suitably engineered to form microcirculatory networks in vitro as well as implanted in vivo, further comparative assessment of more dynamic properties for extended time periods of intended application like extent of vascularization, remodeling, and regression, would be required [49].

For tissues at clinically-relevant volumes, availability of cell sources becomes an important criterion along with current methods of cell expansion to obtain industrial scale cell numbers [50]. It may be noted here that many vascular network forming cell sources (i.e., human umbilical vein endothelial cells (HUVECs)) used in tissue engineering research, are not clinically available and hence more comparative studies are needed with EPCs or MSCs. These have turned the attention to explore alternative sources of like autologous circulating EPCs, induced pluripotent stem cells (iPSCs) and postnatal stem cells, which are being continually experimented to produce stable and mature 3D capillary network [51,52]. It is further imperative to note that different tissue engineering techniques have been applied to fabricate blood vessels including traditional methods like solvent-casting [53], particulate leaching [54], gas foaming [55], fiber bonding [56,57], and phase separation [58,59], while electrospinning and selfassembly are also explored to obtain nano-fibrous scaffolds [60,61]. These techniques offer sparse control over pore size and shape while also lacking in precision requirement of target architectures. To overcome these limitations, rapid prototyping techniques have been introduced such as vat photopolymerization [62,63], material extrusion [64,65], and sheet lamination [66]. Over conventional or any other techniques, they offer the advantage of high level of scaffold-toscaffold consistency and the ability to cater to patient specific geometries [67]. Amongst them, the principal advantage of bioprinting lies in the ability to directly fabricate heterocellular tissue constructs with ease of modulation of cell densities. This advantage is driving researchers to 
explore 3D bioprinting techniques at deeper scales to solve the vascularization problem in tissue engineering [68].

\subsection{Bioprinting for vascular or vascularized tissue fabrication}

In this review, we examine the use of bioprinting in blood vessel fabrication as well as for development of vascularized thick tissue constructs. Bioprinting of vascular constructs can be performed using two main approaches: (i) scaffold-based or (ii) scaffold-free bioprinting. In scaffold-based bioprinting, cells are bioprinted in an exogenous biomaterial (i.e., hydrogel) resembling the target tissue structure, whereas in scaffold-free bioprinting, cells are coaxed to form neo-tissues and then bioprinted without any scaffold support [69]. In the former approach, living cells are encapsulated within hydrogels or decellularized matrix components. In the latter approach, post bioprinting cellular processes, like cell sorting and tissue fusion, which in many ways resemble self-assembly phenomena observed in early embryonic development, are the driving mechanisms in tissue formation [70,71].

\subsection{Scaffold-based Approaches}

In the past few years, scaffold-based bioprinting for vascular tissue fabrication has demonstrated significant advances, principally because several hydrogels can be conveniently bioprinted using the three major bioprinting modalities including EBB, DBB and LBB.

\subsubsection{Extrusion-based Bioprinting of Vascular or Vascularized Constructs}

The general principle of this bioprinting modality lies in continuous extrusion and writing as per a pre-determined program [10,72]. During extrusion, the bioink, in form of cells encapsulated in cylindrical filaments, is deposited in a precise manner into targeted 3D customshaped structures. Tubular structures within core-shell morphologies like alginate shell and a poly(lactic-co-glycolic acid) (PLGA) core are conveniently the fabricated for drug delivery applications using EBB [73]. For EBB, shear-thinning hydrogels, which can flow out of the nozzle at physiological temperatures are preferred as the feeding material [74]. Ideally, the bioink should remain stable in the reservoir during the time of bioprinting and as it is extruded through the nozzle, the viscosity must decrease as a function of increased shear stresses in order to be extruded in the form of a filament. After extrusion, physical- or chemical-crosslinking takes place to facilitate rapid solidification to ensure geometrical fidelity of bioprinted constructs. These requirements put a demanding challenge on choice of bioinks [75]. Early attempts on 
bioprinting vascular tissue using EBB were reported by Smith et al., who utilized a commercial $3 \mathrm{D}$ printer containing two separate cold $\left(2-10^{\circ} \mathrm{C}\right)$ cellular solutions of either bovine aortic endothelial cells (BAECs) suspended in Type 1 collagen and human fibroblasts in PluronicF127. Cell suspensions were bioprinted on a substrate allowing thermal gelation mechanism to take place [76]. Smith and colleagues further demonstrated five-layered arterial constructs using BAECs suspended in Type 1 collagen [77]. Other initial attempts described a bioink composed of magnetic nanoparticles, which were used to control creation of vessels within tissues by applying an external magnetic field [78]. Gradually, EBB efforts for tissue engineering have evolved into direct and indirect extrusion.

\subsubsection{Direct Extrusion}

In this method, cell-laden hydrogels are directly bioprinted as per desired vascular shapes and structures (see Fig. 2A). After bioprinting, the bioink is solidified in a cell friendly environment yielding rigid constructs followed by cellular proliferation and tissue remodeling. Bioink characteristics, including the crosslinking mechanism, shear-thinning properties, and biological and chemical properties of the bioink, are some of the important determinants of cell viability [79]. Early efforts on direct extrusion approach were reflected in a study reported by $\mathrm{Li}$ et al., who showed a method in which the vertical organization of hollow channels was feasible by use of different combinations of gelatin, alginate, chitosan, and fibrinogen hydrogels [80]. They extruded the composite bioink using a dual-nozzle assembly in a $6-8{ }^{\circ} \mathrm{C}$ cooling chamber, allowing sol-gel transition of gelatin followed by crosslinking of other materials using crosslinking agents such as thrombin, calcium chloride $\left(\mathrm{CaCl}_{2}\right)$, and glutaraldehyde for fibrinogen, alginate, and chitosan, respectively. The authors first used a digital model to design a biomimetic liver construct, and bioprinted adipose-derived stromal cells (ADSC) in gelatin/alginate/fibrinogencomposite gelto form vascular channels, while hepatocytes in gelatin/alginate/chitosan composite gel was bioprinted around the vascular constructs to form the liver channel. Bioartificial vessel-like grafts employing the Fab@Home printing system demonstrated by Skardal et al. using tetrahedral pentaerythritol derivatives of polyethylene glycol (PEG) with varying PEG chain lengths [81,82]. Multi-functionalized polymers were used

to co-crosslink thiolated hyaluronic acid and gelatin, which were extruded as well. The authors showed bioprinting of NIH $3 \mathrm{~T} 3$ cells into tubular structures maintaining viability up to four weeks providing strong proof-of-concept for developing vascular constructs. 
Some recent reports further demonstrated the potential of direct bioprinting for vascular tissue biofabrication. For example, Tan and Yeong demonstrated the fabrication of tubular alginate constructs in vertical configuration using multiple nozzles [83]. In their work, a circular structure with $6 \mathrm{~mm}$ radius was designed as the extrusion route for alginate followed by a secondary concentric loop of $4 \mathrm{~mm}$ radius for the dispensing of the crosslinking agent through a micro-valve dispenser. Finally, they have constructed scaffolds up to $15 \mathrm{~mm}$ in length in the vertical configuration as shown in Fig. 2B1-B2. The important advantage of this method is the feasibility of creating large diameter constructs with further potential to create a branching structure; however, this method still requires further optimization in design to accommodate loss in structural accuracy due to shrinkage after the crosslinking process. Recently, Hinton et al customized a MakerBot Replicator for precise deposition of bioink solutions, where they termed their 3D bioprinting technique as freeform reversible embedding of suspended hydrogels (FRESH) [84]. Essentially, the authors printed bioink solutions within a secondary hydrogel support bath to maintain their structural integrity. The support bath played the role of a Bingham plastic, such that it maintained its rigidity at conditions of low shear stress, but as the shear stress increased, the bath started acting as a viscous fluid. In the context of bioprinting, the support bath allowed unresisted movement of the needle due to high shear, whereas after the extrusion (where there is no shear on the hydrogel), the bioink extruded into the bath was kept from spreading out. As shown in Fig. 2C1-C2, the authors demonstrated the direct bioprinting of various bioink combinations comprising of Type 1 collagen, alginate, and fibrin hydrogels with embedded cells like myoblasts and fibroblasts to create constructs like vascular network.

Another commonly used category of direct extrusion is based on the use of a coaxial nozzle assembly as shown in Fig. 3A. Utilizing the concept of wet spinning in bioprinting [8587], vessel-like cellular microfluidic channels in form of hollow filaments were directly bioprinted by our group for the first time in the literature (Figs. 3B1-B2) [88]. In that work, the coaxial nozzle set up consisted of three tubes (feed tube on one hand, and an assembly of outer, and inner tubes on other hand). The hydrogel solution flowed through the feed tube into the space between the outer and inner tubes and after contacting the crosslinking solution, gelation took place instantaneously resulting in tubular conduits [89]. Our group further showed vascular tissue fabrication with human umbilical vein smooth muscle cells (HUVSMCs) loaded in alginate. The efficacy of conduits to support diffusion process was evaluated through perfusion 
and permeability experiments. Cell viability was $84 \%$ after seven days of perfusion culture demonstrating the potential of this method [90,91]. To enhance the mechanical properties of vascular conduits, Dolati et al. demonstrated multi-walled carbon nano-tube (MWCNT) reinforcement (see Figs. 3C1-C2), which enhanced the tensile strength of bioprinted conduits by about 1.5-2.1 times, depending upon the concentration [92]. Though the authors did not report any significant loss of cell viability due to the reinforcement with cell survival values recovering to $70 \%$ after three days of post-bioprinting culture, a limited ECM deposition was observed during prolonged in-vitro culture. Though perfusable conduits up to sub-mm ranges (in diameter) were successfully demonstrated, further work to obtain typical capillary diameters would definitely make the process more versatile. The coaxial extrusion approach was further advanced by Gao et al., who demonstrated concurrent printing of scaffolds with micro-channels [93]. In their work, the dispensing rates and concentrations of sodium alginate and $\mathrm{CaCl}_{2}$ crosslinking solutions were varied to facilitate fusion of adjacent hollow filaments (Figs. 3D1-D3). Bioprinting was performed on a stage that was lowered such that bioprinted constructs were immersed in a $\mathrm{CaCl}_{2}$ pool and allowed for complete gelation. Hollow filament thus coalesced with previously bioprinted filaments, demonstrating the potential for perfusion in larger scale tissue constructs. In another study, Selvaganapathy and Attala designed a modified microfluidic printhead, similar to the coaxial nozzle, for generation of complex vascular constructs by printing gel constructs with embedded hollow channels. Their procedure exploited diffusion of calcium ions which allowed only inner alginate layer to be crosslinked instantaneously while peripheral layers were solidified slowly, only after some lateral spread of alginate solution in the space between two tubular channels had taken place, resulting in eventual amalgamation of one strand of tubular construct with other. This one step strategy allowed the formation of solid gel consisting of hollow tubes embedded inside. The authors found that such unification would occur when adjacent strands were separated up to a distance of $3 \mathrm{~mm}$. The schematic design and a cross section of gel construct containing embedded vascular-like channels is depicted in Fig. 3E1 and E2, respectively [94]. The fabricated vascular like structures were fabricated from extrudable gels such as GelMA with methacrylated hyaluronic acid (HAMA) [94-96]. Recently, using a Novogen MMX Bioprinter ${ }^{\mathrm{TM}}$ loaded with a coaxial nozzle device, GelMA/ 4-arm poly(ethylene glycol)-tetra-acrylate (PEGTA)/sodium alginate/MSC/HUVEC bioink was extruded into 
vascular constructs with outer diameter in the range of 500-1500 $\mu \mathrm{m}$, the inner diameter in the range of 400-1000 $\mu \mathrm{m}$, and the wall thickness in the range of 60-280 $\mu \mathrm{m}$ [97].

\subsubsection{Indirect Extrusion}

In indirect extrusion approach, cell-laden hydrogels are first bioprinted as the base material to create tissue constructs; however, in contrast to direct extrusion, the bulk hydrogel additionally contains a sacrificial hydrogel (i.e., alginate, agarose, gelatin, or Pluronic®) that can be removed post printing either by thermal or chemical means [84] while the bulk hydrogel resin undergoes solidification leaving behind the vascular pattern, as shown in Fig. 4A. Indirect extrusion for vascularized tissue bioprinting was illustrated by work on bioprinting with agarose, which was used as a permissive template for the formation of perfusable channels (Figs. 4B1B2) [98]. In that work, fabrication of tissue constructs containing embedded channels inside the hydrogels was successfully demonstrated using GelMA, star poly(ethylene glycol-co-lactide) acrylate (SPELA), poly(ethylene glycol) dimethacrylate (PEGDMA) and poly(ethylene glycol) diacrylate (PEGDA) polymers. The tissue constructs embedded with microchannels exhibited significantly higher cell viability (more than 90\%) compared to slab hydrogels (60\%) while CD31 immunostaining was performed to show formation of endothelial cell monolayers within perfusable channels [98]. Using the identical methodology, a thrombosis-on-chip model has been demonstrated in which Pluronic sacrificial micro-channels were coated with HUVEC and/or fibroblasts, and embedded within GelMA hydrogels. It was demonstrated that fibroblasts coated in GelMA migrated into the clot and deposited collagen type I when the endothelium was damaged [99].

In a related procedure, but using filament printing technology using a dual-syringe extruder with a heated print-head, cell containing complex structures were bioprinted [100]. In their work, human MSC-loaded alginate-gelatin hydrogels were bioprinted by extruding the bioink at $40^{\circ} \mathrm{C}$ onto a glass substrate maintained at a lower $\left(10^{\circ} \mathrm{C}\right)$ temperature. They created hollow channels through leaching of the support material (gelatin). Bioprinting was performed in two orientations (horizontal and vertical) to find out the effect on the geometry of printed constructs. It was found that vertical alignment orientation produced a larger cross-sectional area than horizontal orientation. Indirect extrusion has demonstrated with Pluronic $₫$ F127 as an aqueous fugitive ink which can be conveniently bioprinted as well as easily removed. The 
authors used GelMA as the matrix as well as the carrier for bioprinting of endothelial cells and fibroblasts. Vascular networks embedded in the GelMA matrix were successfully bioprinted as shown in Figs. 4C1-C2. In an advancement of the work, the same group has also shown long term perfusion of thick vascularized constructs, printed on a 3D perfusable chip as depicted in Figs. 4D1-D3.

\subsubsection{Droplet-based Bioprinting of Vascular or Vascularized Constructs}

In this bioprinting modality, the bioink, which is made up of living cells in culture media or hydrogels, are deposited in the form of droplets with precise control over the position by use of a noncontact bioprinting approach (Fig. 5A) [13,101]. Typically, each droplet contains about a few cells. Thermal-, electrostatic- and piezoelectric-drop-on-demand technologies have been the most widely used approaches among different types of DBB techniques [102,103]. In thermal inkjet bioprinting, bioink droplets are generated by inducing small current to a heating element over a short time interval. The heating results in formation of a bubble, which collapses to provide pressure pulses required for ejection of the bioink from a chamber through a nozzle [104], where the droplet size is determined by the frequency of current pulses, temperature gradient, and viscosity of the bioink, and may vary from 10 to $150 \mathrm{pL}$ [105,106]. In piezoelectric inkjet bioprinting, the current is rather applied to a piezoelectric actuator, which is typically made up of polycrystalline ceramic [107]. As the electric energy is converted to the mechanical energy, the piezo-crystal vibrates and provides a transient pressure, which drives the ejection of the bioink through the nozzle orifice. In inkjet bioprinting, thermal or mechanical stresses are experienced at the nozzle tip during the droplet formation [108]. Thus, cell survival may be affected by the heat shock or membrane disruption $[105,109,110]$. The other principle of DBB is micro-valve bioprinting, in which the bioink is contained in a pressurized fluid chamber whereas an electromechanical valve (consisting of a solenoid coil and a plunger) is turned on or off as per demand. In response to voltage pulses, the solenoid generates a magnetic field causing the plunger to be pulled, opening the nozzle orifice and generating droplets. In DBB techniques, the

print-head can be positioned over the printing bed releasing bioink droplets in a desired pattern with high accuracy [13]. 


\subsubsection{Direct Bioprinting of Vascular Constructs using DBB}

In this approach, tubular structures are bioprinted directly as per design. Initial work with this bioprinting technique was performed for vertical constructs, in which the direction of movement of the nozzle is circumferential to the axis of bioprinted tubular structures. 3D Bioprinting of horizontal tubular structures with high shape fidelity has been made possible by accounting for the concavity distortions of the shape in a stepwise manner, as shown for alginate channels, as depicted in Fig. 5B [111]. One of the pioneering studies using inkjet bioprinting to fabricate tubular hydrogel constructs was published by Kesari et al [112]. In their study, hematopoietic stem cells were entrapped in hydrogels, and crosslinked on demand to produce the patterns in liquid media using a modified Hewlett Packard (HP) printer. The authors were able to differentiate of these cells into multiple different lineages. In an extension of that work, Boland et al showed that multiple layers of cells and alginic gel with uniform pore sizes could be obtained conforming to designed architectures [113]. A bioink solution composed of human microvascular endothelial cells (HMVECs) in fibrin was also utilized for fabrication of microvessel constructs using a modified thermal inkjet printer (HP Deskjet 500) by Cui and Boland [114]. Fifty firing nozzles were mounted on the print head and simultaneously deposited HMVECs and fibrin at droplet volumes of $130 \mathrm{pL}$, and used fibrinogen, thrombin and $\mathrm{Ca}^{2+}$ for rapid solidification of gel post bioprinting. After a week culture, HMVECs showed proliferation along the printed patterns and established cell-cell adhesions. Confluent lining along the alignment with good integrity of printed structure was observed after 21 days giving rise to branched tubular structures mimicking capillaries. By modifying this method with electrostatic printhead, Nakamura et al. demonstrated fabrication of fibers and tubes by expulsion of alginate solutions into a $\mathrm{CaCl}_{2}$ pool, which resulted in formation of well-defined tubes due to rapid diffusion of $\mathrm{Ca}^{+2}$ into alginate solution. This method allowed superior control over tubular conduits, which ranged from 35 to $40 \mu \mathrm{m}$ in wall thickness and 30 to $200 \mu \mathrm{m}$ in inner diameter [115-118].

$\mathrm{Xu}$ and coworkers have recently demonstrated fabrication of zigzag tubes using a piezoinkjet head $[119,120]$. They fabricated alginate conduits using $\mathrm{CaCl}_{2}$ as a complementary support material with hemi-branching bifurcations, which is regarded as a milestone work in fabrication of complex anatomically-correct vascular constructs [121,122]. Their method utilized $\mathrm{CaCl}_{2}$ solution to provide a buoyancy force so that it can be utilized for both as crosslinking agent as 
well as support material facilitating successful bioprinting of these constructs. In continuation of their initial results, Christensen et al. [123] have demonstrated both horizontal and vertical vessel-like bifurcations, wherein $3 \mathrm{~T} 3$ fibroblasts maintained more than $90 \%$ cell viability after an incubation period of $24 \mathrm{~h}$. Valve-based bioprinting of hollow constructs within a liquid support material composed of high-density fluorocarbon has been reported by other groups as well [124-127]. Fluorocarbon solution enabled submerged bioprinting, wherein high buoyancy force allowed floating of soft hydrogels and overcame the concern of obtaining high aspect ratio constructs due to lack of mechanical integrity of hydrogels printed by conventional approaches. Using this technique, typically $30 \mathrm{~mm}$-long constructs (as shown in Fig. 5C) were generated with a cell viability ranging from 96 to $99 \%$, immediately after bioprinting. The same group has extended their earlier work by utilizing contact angle properties of agarose gel to improve the precision of the bioprinting process $[128,129]$.

\subsubsection{Indirect Bioprinting of Vascular Constructs using DBB}

Similar to indirect extrusion, in indirect bioprinting of vascular construct using DBB, the sacrificial bioink (i.e. gelatin) is deposited in cylindrical form followed by bioprinting of cellladen hydrogel layers. The sacrificial material is then liquefied through thermal decrosslinking leaving behind tubular channels while vascularization is obtained by lining endothelial cells within channels. Dai and his coworkers demonstrated this concept by creating perfusable vascular channels using a micro-valve bioprinting [130]. The layer-by-layer approach consisted of first printing a block of collagen layer in a flow chamber, over which gelatin was printed in a strand shape and solidified. This step was followed by bioprinting a layer composed of 1:1 mixture of gelatin and HUVECs in a straight pattern and temperature was kept in room temperature to allow solidification of gelatin. More layers of collagen were then bioprinted over the structure followed by liquefaction of gelatin by incubating at $37^{\circ} \mathrm{C}$ in order to obtain the tubular channels. The flow chamber was then sealed and a gentle flow was started. The bioprinted construct formed a confluent endothelium (Figs. 5D1-D3), while the channel was shown to support the viability of cells which lay up to $5 \mathrm{~mm}$ in distance from the channel under physiological flow conditions [130]. The same group also constructed two fluidic channels within fibrin gel and demonstrated angiogenic sprouting in between as shown in Figs. 5E [21]. 


\subsubsection{Laser-based Bioprinting of Vascular Constructs}

Laser-based bioprinting efforts can be classified under two main categories including the efforts undertaken using (i) processes based on cell transfer technologies and (ii) processes involving photo-polymerization.

The former ones were developed from laser direct-write process [131] and laser-induced forward transfer (LIFT) technologies [132-134]. The important component of LIFT technologies, as shown in Fig. 6A, is the laser energy absorbing material that is stimulated on laser irradiation. The energy-absorbing layer (e.g., titanium or gold) is present on top and along with bioink material present below it comprises the donor layer and resembles a 'ribbon' structure. During bioprinting, laser pulse is focused on a small area between absorbing layer and bioink resulting in subsequent vaporization of a portion of the donor layer, thus causing formation of a high-pressure bubble followed by jet formation [135,136]. The physical mechanism behind this phenomenon has been studied to certain details. Briefly, the absorption of the laser energy results in excitation of the receiving material to a higher vibrational energy state, which can relax to the ground state through mechanism of electron/phonon or phonon/phonon coupling producing localized heat. Localized heat generation then results in vaporization of the bioink and may cause partial or complete volatilization, which in turn causes the focused ejection. Some other mechanisms, like ablation, plasma generation or thermal-acoustic phenomenon may also take place and hence it is necessary to control the laser irradiation parameters precisely [137]. It has been shown that the jet size (around few pL [138]) is governed by the laser pulse energy and the viscosity of the bioink [139], the distance between the collector and donor slide, cell density, bioink wettability, surface tension and the thickness of the bioink [140]. The ejected jets are collected on the receiving layer, which is pre-coated with gel materials, i.e. alginate and Matrigel ${ }^{\mathrm{TM}}$, to absorb the energy of the impacting substances and subsequently cross-linked by thermal or ionic cross-linking.

In processes involving photo-polymerization (such as traditional stereolithography and dynamic optical projection stereolithography), light-induced reactions (by using ultra-fast laser beams) are employed to polymerize and solidify the substrate at the irradiated regions. The beam path of the laser can be programmed according to a computer-aided design (CAD) model (see Fig. 6B). These light-induced photopolymerization reactions can be carried out in the presence of cells and bioactive molecules providing spatiotemporal control over the formation of tissue 
constructs [141,142]. After completion of each layer, the porous table moves down for bioprinting of subsequent layers.

In the literature, a limited number of work has been demonstrated in bioprinting of vascular or vascularized tissue, amongst whom, $\mathrm{Wu}$ and Ringeisen designed branch-stem vessel architectures using a laser-based bioprinter exploiting the single HUVEC encapsulation and deposition capabilities [143]. In their investigations, the authors could observe cells formed interconnections amongst each other within a day. However, these branches had limited stability, which was further improved with the printing of an upper layer of human umbilical vein smooth muscle cells (HUVSMCs) above the HUVEC layer [144]. Potential of LBB was also indicated by Xiong et al., who bioprinted both straight and bifurcated overhang structures using freeform bioprinting of mouse fibroblast-laden sodium alginate, shown in Fig. 6C1-C2 [145]. They observed structurally stable 3D cellular Y-shaped tubes. Post-bioprinting cell survival rates were reported to be above $60 \%$ for both types of the tubes. Using biological laser printing (BioLPTM) platform, Barron et al. [146], Chichkov and coworkers [139], and Ovsianikov et al. [147] independently showed selective seeding of ovine vascular smooth muscle cells and endothelial cells in alginate bioink materials on acrylated PEG scaffolds. Similarly, HUVECs and human MSCs were also bioprinted on a polyester urethane urea (PEUU) patch for cardiac regeneration wherein it was evident that cell patterning through LIFT improved vessel formation [148]. In another work, vascular-like patterning of HUVECs was shown to be successful on collagen or Matrigel $^{\mathrm{TM}}$ loaded porous poly-lactide-co-glycolide (PLGA) stackable biopaper substrates [144]. Hribar et al have recently reported the use of gold nano-rods within cell-encapsulating collagen hydrogels to in-situ produce 3D cell patterns employing a near-infrared femtosecond laser. The nano-rods absorbed the laser beam causing denaturation of adjoining collagen and resulting in formation of 3D channels. A high cell viability (>90\%) was observed using higher writing speeds and lower laser intensities along with supporting endothelial tube formation (see Fig. 6D) demonstrating a suitable technique for vascular tissue engineering [149]. The use of gold nanorods within the cell-laden collagen bioink caused local denaturation of collagen due to highly focused absorption of near-infrared femtosecond laser energy, and resulted in formation of hollow channels. The endothelial cells, which migrated inside the channels could subsequently proliferate, and attained a 3D alignment [150]. To reconstruct 3D vascular morphology, Huang et al have employed a projection printing system called digital micro-mirror device-based 
projection printing (DMD-PP), which creates an optical pattern according to the image acquired from a CAD model. After the pattern is projected, UV light is exposed onto a photosensitive bioink. The substrate is lowered after patterning for each layer using an automated stage. Using DMD-PP, they fabricated user-designed complex micro-structures with channel widths of 25$120 \mu \mathrm{m}$ in highly short time (see Fig. 6E). Though authors proposed this system to study differences in cell types to geometric cues, the same can be adapted for creating vascular-like channels of different diameters for tissue engineering [151].

\subsection{Scaffold-free Bioprinting of Vascular Constructs}

Since the seminal publication of tissue engineering paper in Science by Vacanti and Langer, most of strategies rely on the development of a scaffold support, in which cells are cultured, and expanded in vitro or in vivo [42,152]. Although designed to provide temporary support for cells to grow earlier, scaffolds have evolved to play active role by providing biological, chemical, and mechanical cues to direct cell growth [153]. Certainly, scaffold-based approach has led to some successes into clinical translation [154], and especially for vascular tissue engineering $[155,156]$. However, even after extensive research, ideal biomaterial in terms of immunological reaction, inflammatory reactions in host, degradation rate that matches with neo-tissue formation rate, toxicity of degradation products, fibrosis after material degradation, and mechanical compatibility with the native tissue are yet elusive [69]. Specifically, the inadequate mechanical strength and residual polymer components, which hinder cell growth, have been identified as key bottlenecks for development of engineered vascular grafts $[157,158]$. These deficiencies have led to interest in scaffold-free tissue engineering and thus scaffold-free bioprinting [159-161]. Almost a decade earlier, Kelm et al have shown that when HUVECcoated human myofibroblast micro-tissues (in $\mu \mathrm{m}^{3}$ volumes) were assembled to form macrotissues (in $\mathrm{mm}^{3}$ volumes), a vascular system was developed, which eventually integrated to the host vascular system after implantation in a chicken embryo [162]. The advantages of this method include employing the cell-derived ECM, which is more biocompatible as well as reduces tissue maturation time and fabrication complexities arising out of the scaffold constraints.

Scaffold-free bioprinting of multi-layered small-diameter vascular tubes was reported by Norotte et al. [163] using HUVSMCs, human skin fibroblasts (HSFs) and porcine aortic smooth 
muscle cells (PASMCs), some key steps and results of which are represented in Fig. 7A-B. In their study, cell pellets was incubated in capillary micropipettes (300-500 $\mu \mathrm{m}$ in diameters) and extruded to yield cylindrical bioink materials, which were then sliced into smaller rods and rounded into tissue spheroids. Tissue spheroids were dispensed using a mechanical ram-driven EBB system [69]. In parallel, an agarose mold structure was also 3D printed, where bioprinted spheroids are cast inside the mold. The spheroids then underwent fusion inside the mold, and matured towards vascular tissue, and the mold was then removed leaving behind the tissue. The authors also demonstrated fabrication of bifurcated blood vessels (see Fig. 7B2-B3).

In another study, Tan et al developed a 3D printing technology using alginate microdroplets and calcium-containing substrates to first produce alginate molds (see Fig. 7C1) [161]. Tissue spheroids, consisting of endothelial and smooth muscle cells, were then robotically deposited into the molds, which underwent fusion to form vascular constructs (see Fig. 7C2-C4). The study showed that cell-secreted collagen Type-I played a vital role in tissue formation and maturation. Kucukgul et al recently developed an algorithmic model for toolpath planning for scaffold-free macro-vascular constructs based on patient specific medical images [164]. Their proposed self-supported model was realized with cell pellet consisting of mouse embryonic fibroblast (MEF) aggregates and support structures (agarose) to fabricate aortic tissue-like constructs [165]. In above studies, agarose and alginate molds were chosen since they were inert to cell adhesion and served the purpose of facilitating tissue maturation. Despite these concentrated efforts to bioprint blood vessels, certain issues are still required to be addressed. These include optimization of mechanical properties that will provide adequate mechanical strength for structural integrity and at the same time allow flexibility for suturing. Moreover, scaffold-free vascular bioprinted tissue constructs require long maturation time for the tissue to deposit sufficient collagen and elastin proteins and become mechanically robust. Another major limitation of this approach lies in the scale-up of constructs to make large-tissues without involvement of a temporary molding structure.

\subsection{Bioprinting for Vascularized Tissue Fabrication}

For the past few decades, fabrication of complex tissue and organ constructs have been impeded by the development of suitable technologies, which can ensure adequate cell density, viability and functionality across the constructs (i.e. including the internal anatomy), a goal 
which necessitates the presence of vascularization. For replicating the complex pattern of branched vasculature in length scale assuring long term tissue viability and functionality, 3D bioprinting provides the promising means to achieve the same [166,167]. Importantly, bioprinting can create a pattern of vascular network of desired geometry or dimensional ranges directly utilizing bioactive factors that are responsible for prolonged vascularization. Additionally, bioprinting can be used in tandem to create the vasculature along with other tissue components. Therefore, it can be stated with conviction that bioprinting is one of the most promising engineering approaches to obtain a thick vascularized tissue construct of complex anatomy. Since a design can be created directly from patient-specific medical images, advancement in this technology may ultimately enable construction of anatomically-correct solid organ substitutes. In previous sections, we have discussed the approaches which have been used for vascular tissue fabrication (>1 mm in diameter). Though, some of these approaches were demonstrated for co-culture of vascular endothelial cells with some other cell types like fibroblasts, in the succeeding section, we emphasize the approaches which have been adopted to obtain necessarily heterogeneous, thick tissue constructs for generating clinically-relevant volume of tissues or micro-vascular network $(<100 \mu \mathrm{m})$, which is at the scales lower in dimensions than that of macro-vascular channels.

\subsection{Bioprinting Macro-vascular network}

Bioprinting of macro-vascularized tissue constructs has been attempted by several groups, principally exploring the bioprinting with fugitive ink onto a desired motif, the basic principle of which was described in Section 2. In this regard, Miller et al have reported a method of using a sacrificial carbohydrate glass, which was printed at high temperatures followed by manual infiltration of cells in hydrogels (including PEGDA and acrylate-PEG-RGDS, or fibrinfibrinogen-thrombin or Matrigel or alginate). The hydrogels were then allowed to solidify and the sacrificial material was then dissolved leaving behind vascular-like channels [168]. They developed a sacrificial material based on glucose, sucrose and dextran to fabricate selfsupporting perpendicular lattices, curved filaments, or even Y-junctions with fiber diameters in the range of 150-750 $\mu \mathrm{m}$ printed using an open source 3D printer. Additionally, the carbohydrate glass was coated with PLGA before infiltrating the hydrogels (fibrin, agarose and Matrigel ${ }^{\mathrm{TM}}$ ) so that PLGA can prevent carbohydrate solution to flow through the cell laden polymer layer. After 
seeding endothelial cells, the authors have observed new capillary formation. Further, cellular viability was evident up to approximately $1 \mathrm{~mm}$ around the perfused channels. Such approach was further advanced by Kolesky et al., who co-printed multiple cell-laden, vascular inks, interestingly, under ambient conditions. They demonstrated four-layer constructs by co-printing four inks namely poly(dimethyl siloxane) (PDMS), sacrificial Pluronic F127 and human neonatal dermal fibroblast cells (HNDFs)/10T1/2s/mouse fibroblast-laden GelMA bioink, and a pure GelMA ink at $37^{\circ} \mathrm{C}$. However, they found that since it was not possible to directly perfuse vascularized constructs, fabricated constructs were thus limited in thickness (1-2 mm) and culture times $(<14 \mathrm{~d})$, which are less than clinical requirements [169]. Therefore, to satisfy diverse requirements of biocompatibility, processing ability, integration, and stability, the same group recently reported an advancement in their previous work, in which they used printable cell-laden bioink materials and castable gelatin-fibrinogen blend [170]. Specifically, they first bioprinted the cell-laden bioink (composed of gelatin, fibrinogen, and either of HUVECs, HNDFs, or hMSCs as cellular component) and a fugitive ink (composed of Pluronic and thrombin) on silicone perfusion chips specially fabricated on a glass substrate. A composite hydrogel containing gelatin, fibrinogen, thrombin, and transglutaminase was then printed. Pluronic containing ink was melted and removed upon cooling thus yielding a channel network, which was subsequently endothelialized and perfused. The authors could fabricate thick, vascularized tissue constructs recreating the geometry, complexity, heterogeneity, and longevity of human tissues, which was capable of being perfused for a long duration (> 6 weeks) and showed differentiation of MSCs toward an osteogenic lineage. Recently, using the same Pluronic as a sacrificial ink, Kang et al showed the fabrication of large-scale bone (mandible), cartilage (ear) and skeletal muscle constructs by developing an integrated tissue-organ printing system [171]. Firstly, the team obtained the shape of desired constructs by processing radiological images. In this work, poly(caprolactone) (PCL) was used as a supporting structural frame which conferred mechanical stability to the construct. Authors printed different patterns of PCL around the composite hydrogel composed of cells to optimize the most stable structures. On the other hand, Pluronic was used as a fugitive ink, which was dissolved after crosslinking of the bioink yielding a porous structure. The work demonstrates successful fabrication of large-scale tissue constructs maintaining both mechanical strength and cell viability at the same time. 
In order to develop 3D perfusable organ modules, our team further introduced a microfabrication approach to generate tissue strands as a scalable scaffold-free bioink [172,173]. In that work, apart from cell-laden tubular alginate conduits, pellets of cells were injected into tubular conduits to fabricate tissue strands. When the tissue strands matured, they were used as a bioink for scale-up tissue bioprinting [174]. Our group previously devised a hybrid bioprinting approach for assembling both vasculature network and tissue-specific strands on a single MultiArm BioPrinter platform [175]. While cells and their specific ECM form the strands or building blocks for scale-up organ fabrication [172], macro-scale single continuous luminal form was printed in parallel. The bioprinter used for this study allowed tissue self-assembly along a length of $1.5 \mathrm{~cm}$ of smooth muscle vasculature, where fibroblast tissue strands fused to each other after one day in culture while maturation was obtained in a week. Detailed histological observation also proved complete attachment of the tissue to the vasculature and tight adhesion to the smooth muscle matrix confirmed proof-of-concept for large-scale hybrid tissue bioprinting [176]. This work demonstrated an innovation on how both scaffold-based and scaffold-free bioprinting can be integrated into a single fabrication modality to obtain scalable constructs.

\subsection{Bioprinting Micro-vascular Network}

From the above discussion, it can be appreciated that vascularization is highly vital for cells to maintain their metabolic functions inside large-volume tissue constructs; however, the vascular system is characterized by a multi-scale organization, which is not practical by most bioprinting technologies. To fulfill this, bifurcated vessels should ideally be fabricated with capillaries to mimic the natural vascular anatomy. In studies addressing capillary formation, heterogeneous constructs incorporating goat endothelial progenitor cells (EPCs) have been reported by Fedorovich et al fabricated to obtain engineered bone grafts with vascularization [177]. In their work, composite Matrigel ${ }^{\mathrm{TM}}$ and alginate-based bioink containing both EPCs and multi-potent stromal cells (MPSCs) were fabricated and also evaluated post implantation. After six weeks, bone formation and prominent vascularization were observed. However, the mechanical integrity of these constructs was sub-optimal for surgical implantation. Similarly, multi-head tissue/organ building system was employed for capillarized tissue bioprinting [35]. The system was used to print 3D cell-laden construct for liver tissue engineering. While PCL was used as a frame material, the bioink was composed of three cell types - hepatocytes, HUVECs, and human normal lung fibroblasts with collagen. The bioink was infused into the 
PCL to induce the formation of capillary-like networks and hepatic tissue growth. The study highlighted that capillarization could accord several important advantages including improved survival of hepatocytes due to the presence of non-parenchymal cells (underlying the need for bioprinting hetero-cellular constructs), and an improvement in protein secretion and metabolism of hepatocytes, overall emphasizing the potential of this method for liver regeneration. A customized Bioassembly Tool (BAT) consisting of two controlled dispensing units, a servodisplacement and another pneumatic pump has been used for extrusion of Pluronic-F127 sacrificial channels in a collagen microvascular construct with an aim to study mechanisms of post-angiogenesis microcirculatory architecture formation. The results indicated the superior role of architectural cues in controlling the tissue environment over the role of vascular elements themselves [178].

Generating clinically relevant volumes of complex organs involves a much higher level of sophistication comprising various types of cells arranged in a specific hierarchy, a multi-scale vasculature network consisting of stroma and parenchyma, apart from presence of lymphs and nerves to complete the functionality. Thus, researchers may explore bioprinting tissue specific cells in a scaffold-free pre-vascularized spheroid form followed by coating with layer of angiogenic promoting material like fibrin. Formation of a continuous vessel like channels within the spheroid assembly coupled with elongation of sprouts, and their anastomosis between two spheroids can be observed [20]. Finally, sprouting of these capillaries from spheroids to the vessels makes it possible to bridge the gap and render a fully contiguous vascular network [10]. In light of the results of these studies, it also becomes imperative that post bio-printing processes concerning cell assembly [179] and accelerated tissue maturation will govern the rate of vascularization in tissue constructs [180].

\section{Comparison of Different Bioprinting Modalities within the Context of Vascular or Vascularized Tissue Bioprinting}

Although various approaches can be used in fabrication of vascular or vascularized tissues, their performance in generating functional, anatomically-correct, physiologicallyrelevant, mechanically and structurally stable, and biologically appealing constructs vary considerable. Therefore, the appropriate approach should be selected and utilized depending on the target organ, its anatomical complexity, physiology, and biological function. 
Extrusion-based bioprinting enables fabrication of vascular constructs that are volumetrically large as well as possess high aspect ratio. As EBB facilitates scale-up fabrication of tissue constructs compared to other bioprinting modalities including DBB and LBB [10], larger vascular constructs can be practical to build as demonstrated using all EBB approaches such as direct [172] and indirect [181] bioprinting. Coaxial extrusion of vascular network particularly generates high aspect ratio vascular constructs, virtually unlimited in length, as already demonstrated in our earlier work [91]. Despite its practicality and tight control on the dimensions, biofabrication of bifurcated channels using the coaxial extrusion approach is highly challenging as only a manual approach was demonstrated to generate branching points [91]. Fabrication of bifurcation is possible using direct or indirect bioprinting techniques, where the vasculature can be built layer by layer instead of extruding it directly. The other great benefit of EBB is the indirect bioprinting approach, where fugitive inks can be easily bioprinted in highly complex patterns generating open lumens for perfusion. Despite the great flexibility in complexity of channels, a native vascular network is oriented in 3D space rather than on a single plane and bioprinting of such vascular tree with 3D orientation in Cartesian space has yet to be performed. As 3D bioprinting is a layer-by-layer fabrication approach, there is a finite thickness of each layer and incrementing the position of the fugitive ink in each layer may induce stairstepping effect [182], which in turn may generate occlusion or turbulence in the flow when the fugitive ink is removed.

Although a substantial progress has been made in indirect bioprinting approach for vascularized tissue bioprinting as it is highly convenient to build channels in bulky or slab gels as compared to free-standing channels, such tissue construct may exhibit challenges when they are utilized in regenerative medicine and transplantation areas. The major reason is that although lining endothelial cells within channels represents an endothelium with tight junctions, native blood vessels have multiple layers as discussed in anatomical description of blood vessels early. Therefore, it is highly challenging to transplant such a construct as the vascular pedicle in the transplant site may not be easily sutured to the inlet and outlet of the construct. Besides, as the bulk hydrogel is prone to degrade, with different rate of degradation depending on the bioink type utilized, vascular channels can quickly lose their rigidity, and can enlarge and collapse resulting in failures in blood flow in vivo. Thus, vascular networks should be built with intimal, medial and adventitia layers embedded within bulk hydrogels, which has not been demonstrated 
yet. One of the major limitations in EBB is its lack of high resolution and precision in printing cells. As bioprinting capillaries at the given cell level definitions is highly challenging using any of the bioprinting approaches demonstrated so far, current efforts in generating such microcapillaries using angiogenesis-driven mechanism is also highly attractive approach for persuasion [183]. Previous research work in DBB of endothelial cells demonstrated that when cells were deposited in patterns, which cannot be tightly controlled using manual approaches or even using EBB, they could generate tubular conduits [114]. Thus, generation of microcapillaries within EBB constructs has been a challenge so far.

Droplet-based bioprinting has the advantage of generating high-resolution constructs, which is of great value for micro-capillary network development. Despite its greater benefits in bioprinting well-defined structures and high-resolution patterns with the ability to co-culture multiple cell types in a high throughput manner, DBB suffers from enabling larger scale constructs as bioprinting in 3D is of a challenge [13]. By using the approach in bioprinting tubular construct into a crosslinker pool using the advantage of chemical crosslinking process, low aspect ratio vascular constructs have been demonstrated [122,124]. Despite these efforts, characterization of vascular constructs including mechanical testing (tensile, suture retention and burst pressure) and long-term performance under perfusion culture has yet to be performed. In addition, as these vascular constructs are free-standing in the crosslinker pool, integration of the parenchymal tissue around the vascular construct is a critical barrier in order to translate the technology from basic research to functional vascularized tissue fabrication. A recent work demonstrated the indirect DBB for vascularized tissue construct fabrication using sacrificial biomaterials such as gelatin [21], thus DBB has the potential to facilitate fabrication of tissue models for pharmaceutical testing and cancer research [184]. For inkjet bioprinting, the upper limit for the bioink viscosity is recommended to be in the order of $0.1 \mathrm{~Pa}^{-1} \mathrm{~s}^{-1}$, while highly viscous hydrogels are not ideal materials for processing by this technique as they can clog the nozzle tip $[185,186]$. Moreover, low reproducibility, extreme shear stress within the nozzle, undesired cell aggregation and settling in ink reservoir, formation of clogs at the nozzle tip, and the limited choice of compatible bioink materials are other disadvantages and challenges associated with this bioprinting technology $[1,125,127,187]$. This technology, however, offers a great potential to overcome many of the inherent problems faced by the tissue engineering researchers, providing 
the ability to eject droplets of very small size composed of several bioink materials and pattern them spatially on demand [124-127].

Using processes involving photopolymerization, vascular tissue constructs have been built with well-defined architectures demonstrating native like branching configuration [150]; however, these approaches possess several limitations impeding the development of biologically superior constructs. First of all, bioprinting at the sufficient cell density that is close to native histological composition is not quite feasible. In addition, due to the limited number of photocurable bioink materials as well as the need for photo-initiators (that are toxic in general) [188], these processes do not support bioprinting vascular constructs that are mechanically and structurally stable and strong. The use of photo-initiators, such as Irgacure 2959 [189,190], limits the mechanical properties of the bioprinted constructs as the photo-initiators should be water soluble. The LBB processes based on cell transfer (e.g., LIFT), on the other hand, have been recently utilized in fabrication of vascular constructs using a similar concept applied DBB, where the bioink is deposited into a crosslinker pool [145]. In general, processes based on cell transfer such as laser-guidance direct writing, matrix-assisted pulsed-laser evaporation-direct write and LIFT are highly challenging to generate 3D larger tissue constructs due to the limited number of compatible bioink materials (i.e., Matrigel ${ }^{\mathrm{TM}}$, alginate, gelatin) and lack of appropriate process setup facilitating rapid crosslinking of mechanically resilient constructs. Compared to EBB and DBB, LBB avoids shear stress induced cell damage [191]. Laser-based bioprinting prevents cells from any shear-stress related damage due to nozzle-free nature, thus rendering high cell viabilities in general (95\% and above) [192-194]. In addition, LBB can be used to print bioink materials with high viscosity and a wider range of bioink materials i.e., fibrous proteins [195]. Though the salient characteristics of LBB hold significant promise for tissue engineering, the complications and unfavorable effects of laser irradiation on different cell types are not yet comprehensively unraveled [191]. Moreover, high-intensity and -resolution diode lasers are more expensive than equipment used in other bioprinting modalities, and the control of the laser printing process is highly difficult to manage. Thus, there is currently no laser-based bioprinters commercially available, as they are less user-friendly and more complicated and expensive in comparison to other types of bioprinters.

Scaffold-free bioprinting of vascular constructs has been a very exciting direction in building vascular grafts that are histologically close to native counterparts, where multiple-layers 
can be easily incorporated with controlled cell type and population [163]. Further cultivation of these vascular constructs in perfusion bioreactors with pulsatile flow can improve their mechanical properties and induce the appropriate mechanical stimulation to deposit more collagen and elastin fibers in the desired orientation, which are essential for long-term function after implantation. A recent work also demonstrated in-vivo endothelialization of scaffold-free bioprinted vascular grafts in murine models, demonstrating further advantageous of using this approach; however, long term patency and performance of such grafts still needs to be investigated [196].

Table 1 compares existing bioprinting methods used in vascular tissue biofabrication along with cell types; bioink or bioprinters utilized in each method: 
Table 1: A comparison of different bioprinting methods for vascular tissue fabrication.

\begin{tabular}{|c|c|c|c|c|c|}
\hline Method & $\begin{array}{c}\text { Mechanism } \\
\text { (bioprinted } \\
\text { modalities used) }\end{array}$ & Cell types bioprinted & Bioink or substrate used & Bioprinters used & Remarks \\
\hline \multirow{3}{*}{ 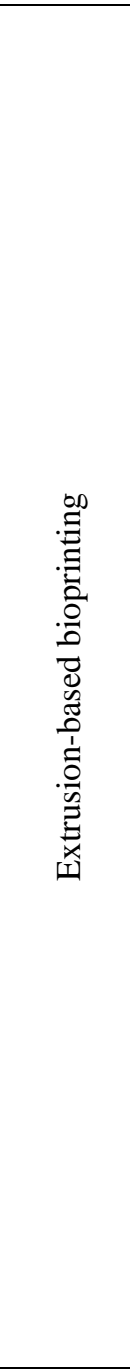 } & Direct bioprinting & $\begin{array}{l}\text { Murine fibroblasts (NIH 3T3) [81,82], } \\
\text { human hepatoma cells (HepG2 C3A) } \\
\text { [81,82], human intestinal epithelial } \\
\text { cells (Int 407) [81,82], C2C12 } \\
\text { myoblasts [84], MC3T3 [84], adipose- } \\
\text { derived stromal cells(ADSCs) and rat } \\
\text { hepatocytes [79], cartilage progenitor } \\
\text { cells(CPCs) [84,88], HCASMC [92], } \\
\text { human umbilical vein endothelial cells } \\
\text { (HUVECs) [91,169], human umbilical } \\
\text { vein smooth muscle cells (HUVSMC) } \\
\text { [173], Escherichia Coli K12 cells [89], } \\
\text { L929 mouse fibroblasts [98] }\end{array}$ & $\begin{array}{l}\text { Pentaerythritol derivatives of } \\
\text { polyethylene glycol (PEG) [81,82], } \\
\text { fibrinogen [84], alginate/ chitosan } \\
\text { [88], } \\
\text { gelatin/alginate/fibrinogen(GAF) } \\
\text { [80], gelatin/alginate/chitosan } \\
\text { (GAC) [80], sodium alginate and } \\
\text { calcium chloride }[83,89,91- \\
95,169,173]\end{array}$ & 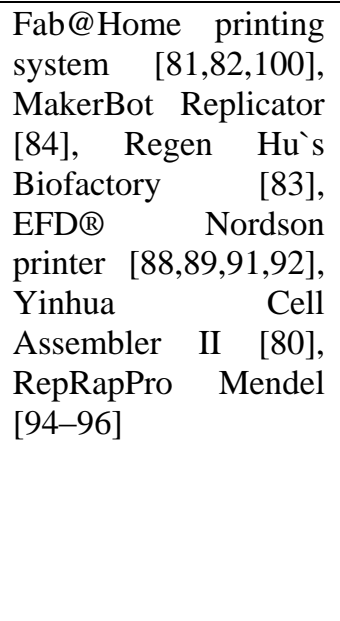 & 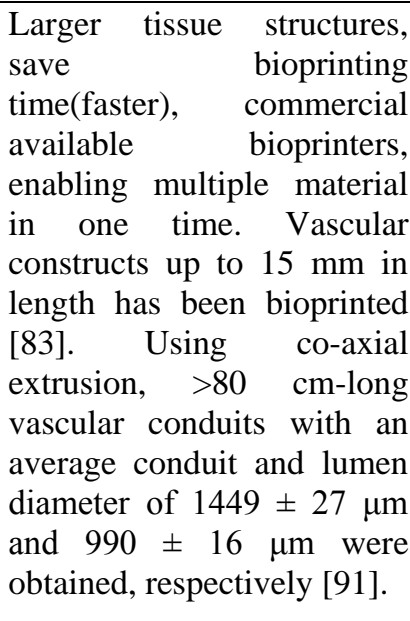 \\
\hline & $\begin{array}{l}\text { Indirect } \\
\text { bioprinting }\end{array}$ & $\begin{array}{l}\text { MC3T3 [100], human umbilical vein } \\
\text { endothelial cells (HUVECs) } \\
\text { [100,170,177], human neonatal dermal } \\
\text { fibroblasts (HNDFs) [170], human bone } \\
\text { marrow-derived mesenchymal stem } \\
\text { cells (hMSCs) [170], human } \\
\text { mesenchymal stem cells (hMSCs) [55], }\end{array}$ & $\begin{array}{l}\text { Star poly(ethylene glycol-co-lactide) } \\
\text { acrylate } \text { (SPELA) [98], } \\
\text { poly(ethylene glycol) dimethacrylate } \\
\text { (PEGDMA) [98], poly(ethylene } \\
\text { glycol) diacrylate (PEGDA) [98], } \\
\text { silicone elastomer/ Pluronic } \\
\text { F127/methacrylated } \\
\text { (GelMA) [170], } \\
\text { F127/thrombin [170], methacrylated } \\
\text { gelatin (GelMA) } \\
\text { alginate/gelatin [55] }\end{array}$ & 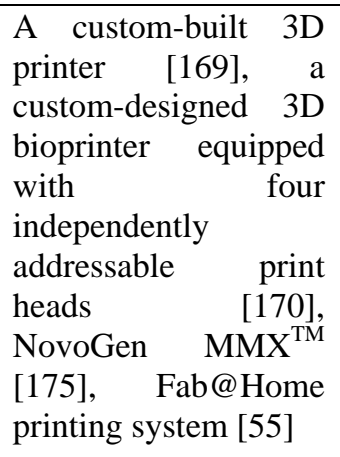 & $\begin{array}{l}\text { Micro-channels with } \\
\text { diameter ranging from } 150 \\
\mu \mathrm{m} \text { to } 1 \mathrm{~mm} \text { were fabricated } \\
\text { [98]. Heterogeneous tissue } \\
\text { constructs }(>1 \mathrm{~cm} \text { thick and } \\
10 \mathrm{~cm}^{3} \text { in volume) were } \\
\text { demonstrated [169]. }\end{array}$ \\
\hline & $\begin{array}{l}\text { Scaffold-free } \\
\text { bioprinting }\end{array}$ & $\begin{array}{l}\text { Chinese Hamster Ovary cells (CHOs) / } \\
\text { human umbilical vein smooth muscle } \\
\text { cells (HUVMSCs)/ human skin } \\
\text { fibroblasts (HSFs)/ porcine aortic } \\
\text { smooth muscle cells (PASMCs) [175], }\end{array}$ & 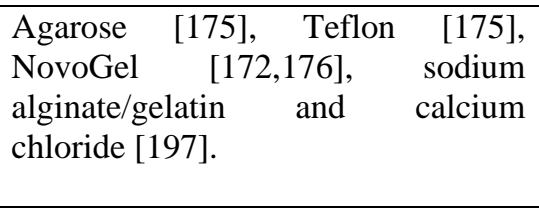 & $\begin{array}{l}\text { Novogen Bioprinter } \\
{[172,175,176], \quad \text { The }} \\
\text { Palmetto 3D Printer } \\
{[161]}\end{array}$ & $\begin{array}{l}\text { Multicellular spheroids or } \\
\text { cylinders ( } 300 \text { to } 500 \mu \mathrm{m} \\
\text { diameter) were bioprinted } \\
\text { and post-printing fusion } \\
\text { resulted in single- and }\end{array}$ \\
\hline
\end{tabular}




\begin{tabular}{|c|c|c|c|c|c|}
\hline & & $\begin{array}{l}\text { mouse embryonic fibroblast (MEF) } \\
{[172,176], \text { human aortic smooth muscle }} \\
\text { cells (hSMCs)/human } \\
\text { umbilical vein endothelial cells } \\
\text { (HUVECs) }\end{array}$ & & & $\begin{array}{l}\text { double-layered } r \text { small } \\
\text { diameter vascular tubes in } \\
0.9 \text { to } 2.5 \mathrm{~mm} \text { outer } \\
\text { diameter range }[163] .\end{array}$ \\
\hline \multirow{2}{*}{ 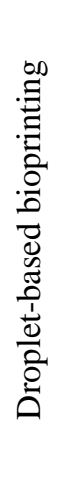 } & Piezo inkjet & $\begin{array}{l}\text { Rat smooth muscle cells (SMCs) [113], } \\
\text { NIH3T3 mouse fibroblasts [123] }\end{array}$ & $\begin{array}{l}\text { Sodium alginate/gelatin and calcium } \\
\text { chloride [113], sodium alginate and } \\
\text { calcium chloride }[121,124]\end{array}$ & $\begin{array}{lr}\text { Modified- } & \text { HP697c } \\
\text { inkjet } & \text { Printer } \\
{[112,113],} & \text { MicroFab } \\
\text { MJ-ABL } & \text { piezoelectric } \\
\text { inkjet } & \text { printhead } \\
{[121,123]} & \end{array}$ & $\begin{array}{l}\text { Heterocellular } \quad \text { tissue } \\
\text { patterning with small } \\
\text { droplets (less than } 100 \mu \mathrm{m})\end{array}$ \\
\hline & $\begin{array}{l}\text { Valve-based } \\
\text { inkjet }\end{array}$ & $\begin{array}{l}\text { Human umbilical vein endothelial cells } \\
\text { (HUVECs) }[21,130]\end{array}$ & $\begin{array}{l}\text { Collagen/gelatin } \\
\text { fibrinogen/thrombin [130] }\end{array}$ & $\begin{array}{l}\text { Custom-built printer } \\
{[21,130]}\end{array}$ & $\begin{array}{l}\text { The smallest droplet size is } \\
100 \mu \mathrm{m} \text {, but it enables } \\
\text { printing materials like } \\
\text { fluidic channel with } 0.7-1.5 \\
\text { mm width and } 0.5-1.2 \mathrm{~mm} \\
\text { height) [130]. }\end{array}$ \\
\hline 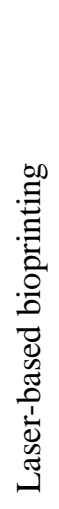 & $\begin{array}{l}\text { Laser-assisted } \\
\text { bioprinting }\end{array}$ & $\begin{array}{l}\text { Murine fibroblasts (NIH 3T3)[143], } \\
\text { bend3 endothelial cells [144] }\end{array}$ & $\begin{array}{l}\text { Sodium alginate and calcium } \\
\text { chloride [143], collagen [144] }\end{array}$ & $\begin{array}{l}\text { ExciStarexcimer laser } \\
\text { [143], NIR laser beam } \\
\text { [144] }\end{array}$ & $\begin{array}{l}\text { It is quite expensive } \\
\text { modality, high precision, } \\
\text { not able to get multiple } \\
\text { material droplet. Micro- } \\
\text { channel widths of } 25-120 \\
\mu \mathrm{m} \text { were obtained [151]. }\end{array}$ \\
\hline
\end{tabular}




\subsection{Future Perspectives}

Vascularization is one of the most important factors that determine success of engineered constructs to remain viable as it ensures nutrients and oxygen supply for metabolizing cells; however, fabrication of vascular network has persisted as a challenge in tissue engineering. Meanwhile, 3D bioprinting has emerged as a promising tool to develop fully biomimetic tissue constructs and organs for clinical applications. In addition, high throughput methods to produce in-vitro models for drug efficacy, metabolism and toxicity screening assays would also be obtained with 3D bioprinting. This technique confers unparalled advantages to mimic anatomical features and functions of the native tissue. Though several initial successes on bioprinting vascularized tissue constructs have been reported, further developments are necessary for widespread implementation by practicing clinicians. For one, it would be expected that efforts towards direct in-vivo bioprinting of biomimetic constructs to replace and accelerate regeneration of compromised organ parts would eventually be realized in clinics. Development of robotic instrumentation technologies for simplified, portable bioprinters at one hand and scalable automated biofabrication production lines at the other hand would hence be the focus of future works. Future bioprinters in clinics would be required to fabricate vascularized tissues with greater speed than that are used in laboratories to reliably manufacture constructs of clinically-relevant volumes and meet patients' demands. While one approach would be to fabricating mini-tissue blocks and then scaling up by joining of the mini-tissue blocks to clinically-relevant volumes, the other approach may employ bioprinting of macro-scale vascular network in tandem with micro-vascularized tissue strands $[109,174,180]$. The recent introduction of a novel scalable bioink, "tissue strands," for scaffold-free bioprinting is hence an important advancement towards obtaining vascularized tissues in the future [174]. In parallel, automated robotic based methodology for generating multilayered small diameter tubular vessels of lumen diameters of 0.5-6 mm and individual layer thickness of $<400 \mu \mathrm{m}$ composed of GelMA, alginate and chitosan are also expected to compliment bioprinting methods [198]. It must be noted here that recent several reports showed how mechanical stiffness of matrices govern differentiation of progenitor or stem cells. Therefore, it needs future investigations to see if materials with tunable mechanical properties are developed and if these specific mechanical properties are bioprinted at the clinical scale. Herein, another important consideration is not only creation of vascular network but also assuring stability of the same with the shape fidelity. Clinicians will expect that 
immediately after vascularization requirements are met in engineered constructs, nerve supply networks are also built to obtain innervated tissues.

Another dimension that requires extensive work in the domain of bioprinting of vascularized tissues is that the resolution of spatial and temporal control that can be attained over the positioning of cells, proteins and even genetic materials should be proposed. In respect to the temporal control, 3D bioprinting approaches may eventually evolve into 4D bioprinting $[199,200]$. In 4D bioprinting, "time" factor is integrated as the fourth dimension and allows responsive cells and materials to alter their functionalities and shape in response to external stimuli. Thus, printed constructs can undergo appropriate reorganization to improve their functionality. However, it is also to be borne in mind that native vasculature is multi-scalar in nature and future bioprinting technologies should be capable enough to produce vascularization at multi-scale dimensions from arteries/veins down to capillaries. However, with current bioprinting technologies, it is difficult to bioprint sub-micron capillaries. Therefore this should be the aim of future endeavors so that micro-vascular network can be printed in tandem with the rest of macro-sized tissue. Moreover, blood vessels should not only contain endothelial cells but also, smooth muscle cells which are important to provide patency and mechanical strength, concentric bioprinting of endothelial and smooth muscle cells should therefore be an important area of investigation in the future. Finally, bioprinted constructs would be required to be sutured and remain integrated with the perfusion system of the host without collapsing or occlusion.

Apart from the scientific challenges, 3D bioprinting technology will also have to face the imminent regulatory and intellectual property concerns. Presently, bioprinting technology is not classified as such; however, proper classification under device/biological category would be required to be made for which standardization of bioprinted constructs will be required. Similarly, for commercial benefits to investors, proper intellectual protection is required. Bioprinting processes and products are discernibly different from natural tissues or tissue formation process, and importantly involve human intellectual intervention, and therefore could be considered for intellectual protection. These facts would be required for consideration for successful clinical translation. 


\subsection{Conclusion}

Though the realm of 3Dbioprinting has brought tremendous advances to obtain vessel structures with sound structural and functional integrity, it can still be observed that fabricating clinically relevant vascular and vascularized tissue constructs are still some milestones away. Specifically, newer insights in directions of enhancing resolution, and obtaining more anatomically accurate constructs while allowing scaling up of bioprinted tissues are expected to provide potential solutions. Gradually, it may be expected that separate research on materials and cellular bioink materials for vascularization may cede place to more integrated and holistic approaches for developing bioprinters for vascularized tissue fabrication. Thus, the development of fully automated robust instrumentation, integrated with intricate modeling and design process software, would be critical to ensure that new vascular channels are assimilated with host vasculature. Further, bioprinting of complex pattern of vascular network at multiple scale ranges would be a challenge. Presently, prevalent technologies fall short of generating an intact capillary network at the single cell level. To achieve this goal, dispensing technology component

of bioprinters will have to evolve to advance the spatial resolution. Ideally, tissue specific bioink materials would be required to be formulated with vascularization-directing bioactives and operated under high throughput and high resolution bioprinters to allow rapid fabrication of vascularized thick tissues at the clinically-relevant volumes.

\section{Acknowledgements}

This work has been supported by National Science Foundation CMMI Awards 1349716 and 1462232, and a grant from Osteology Foundation. The authors are grateful to the support from the Turkish Ministry of National Education for providing graduate scholarship to Bugra Ayan. The authors also acknowledge Department of Science and Technology, Government of India, INSPIRE Faculty Award to Dr. Pallab Datta. In addition, the authors are grateful to Hemanth Gudapati for his assistance with Figure 1. The authors also thank Tasoglu Lab at University of Connecticut for the bioprinter concept image used in Figure 1 and the graphical abstract. The authors confirm that there are no known conflicts of interest associated with this publication and there has been no significant financial support for this work that could have influenced its outcome. 


\section{References}

[1] C.L. Ventola, Medical Applications for 3D Printing: Current and Projected Uses, Pharm. Ther. 39 (2014) 704-711. http://www.ncbi.nlm.nih.gov/pmc/articles/PMC4189697/.

[2] J.A. Greene, Do-It-Yourself Medical Devices - Technology and Empowerment in American Health Care, N. Engl. J. Med. 374 (2016) 305-308. doi:10.1056/NEJMp1511363.

[3] A. Marro, T. Bandukwala, W. Mak, Three-Dimensional Printing and Medical Imaging: A Review of the Methods and Applications, Curr. Probl. Diagn. Radiol. 45 (2016) 2-9. doi:10.1067/j.cpradiol.2015.07.009.

[4] H.H. Malik, A.R.J. Darwood, S. Shaunak, P. Kulatilake, A.A. El-Hilly, O. Mulki, A. Baskaradas, Three-dimensional printing in surgery: a review of current surgical applications, J. Surg. Res. 199 (2015) 512-522. doi:10.1016/j.jss.2015.06.051.

[5] N. Scoutaris, S. Ross, D. Douroumis, Current Trends on Medical and Pharmaceutical Applications of Inkjet Printing Technology, Pharm. Res. 33 (2016) 1799-1816. doi:10.1007/s11095-016-1931-3.

[6] M. Nagata, H. Hoshina, M. Li, M. Arasawa, K. Uematsu, S. Ogawa, K. Yamada, T. Kawase, K. Suzuki, A. Ogose, I. Fuse, K. Okuda, K. Uoshima, K. Nakata, H. Yoshie, R. Takagi, A clinical study of alveolar bone tissue engineering with cultured autogenous periosteal cells: coordinated activation of bone formation and resorption., Bone. 50 (2012) 1123-9. doi:10.1016/j.bone.2012.02.631.

[7] J. He, F. Xu, Y. Liu, Z. Jin, D. Li, Advanced tissue engineering strategies for vascularized parenchymal constructs, J. Mech. Med. Biol. 14 (2013) 1430001. doi:10.1142/S0219519414300014.

[8] J.G. Nemeno-Guanzon, S. Lee, J.R. Berg, Y.H. Jo, J.E. Yeo, B.M. Nam, Y.G. Koh, J.I. Lee, Trends in tissue engineering for blood vessels, J. Biomed. Biotechnol. 2012 (2012) 956345. doi:10.1155/2012/956345.

[9] S. Knowlton, A. Joshi, B. Yenilmez, I.T. Ozbolat, C.K. Chua, A. Khademhosseini, S. Tasoglu, Advancing cancer research using bioprinting for tumor-on-a-chip platforms, Int. J. Bioprinting. 2 (2016) 3-8. doi:10.18063/IJB.2016.02.003.

[10] I.T. Ozbolat, M. Hospodiuk, Current advances and future perspectives in extrusion-based bioprinting., Biomaterials. 76 (2016) 321-43. doi:10.1016/j.biomaterials.2015.10.076.

[11] W. Peng, D. Unutmaz, I.T. Ozbolat, Bioprinting towards Physiologically Relevant Tissue Models for Pharmaceutics, Trends Biotechnol. 34 (2016) 722-732. doi:10.1016/j.tibtech.2016.05.013.

[12] I.T. Ozbolat, K.K. Moncal, H. Gudapati, Evaluation of bioprinter technologies, Addit. Manuf. (2016). doi:10.1016/j.addma.2016.10.003.

[13] H. Gudapati, M. Dey, I. Ozbolat, A comprehensive review on droplet-based bioprinting: Past, present and future, Biomaterials. 102 (2016) 20-42. doi:http://dx.doi.org/10.1016/j.biomaterials.2016.06.012.

[14] J.P. Stegemann, S.N. Kaszuba, S.L. Rowe, Review: Advances in Vascular Tissue Engineering Using Protein-Based Biomaterials, Tissue Eng. 13 (2007) 2601-2613. doi:10.1089/ten.2007.0196. 
[15] P. Berillis, The Role of Collagen in the Aorta's Structure, Open Circ. Vasc. J. (2013) 1-8. doi:10.2174/1877382601306010001.

[16] H. Ardalani, A.H. Assadi, W.L. Murphy, Structure, Function, and Development of Blood Vessels: Lessons for Tissue Engineering, in: W. Cai (Ed.), Eng. Transl. Med., Springer London, London, 2014: pp. 155-182. doi:10.1007/978-1-4471-4372-7_6.

[17] S.Y. Yuan, R.R. Rigor, Regulation of Endothelial Barrier Function, Morgan \& Claypool Life Sciences, San Rafael, CA, 2010. doi:10.4199/C00025ED1V01Y201101ISP013.

[18] J.R. Levick, An introduction to cardiovascular physiology, Butterworths, 1991.

[19] M.F. Leong, J.K.C. Toh, C. Du, K. Narayanan, H.F. Lu, T.C. Lim, A.C.A. Wan, J.Y. Ying, Patterned prevascularised tissue constructs by assembly of polyelectrolyte hydrogel fibres, Nat Commun. 4 (2013). http://dx.doi.org/10.1038/ncomms3353.

[20] I.T. Ozbolat, Bioprinting scale-up tissue and organ constructs for transplantation, Trends Biotechnol. 33 (2016) 395-400. doi:10.1016/j.tibtech.2015.04.005.

[21] V. Lee, A. Lanzi, H. Ngo, S.-S. Yoo, P. Vincent, G. Dai, Generation of Multi-scale Vascular Network System Within 3D Hydrogel Using 3D Bio-printing Technology, Cell. Mol. Bioeng. 7 (2014) 460-472. doi:10.1007/s12195-014-0340-0.

[22] H.C.H. Ko, B.K. Milthorpe, C.D. Mcfarland, Engineering thick tissues - the vascularisation problem, Eur. Cells Mater. 14 (2007) 1-19. doi:10.22203/eCM.

[23] C. Maes, T. Kobayashi, M.K. Selig, Osteoblast precursors, but not mature osteoblasts, move into developing and fractured bones along with invading blood, Dev. Biol. 19 (2010) 319-344. doi:10.1016/j.devcel.2010.07.010.

[24] J. Hatch, Y. Mukouyama, Spatiotemporal mapping of vascularization and innervation in the fetal murine intestine, Dev. Dyn. 244 (2015) 56-68. doi:10.1002/dvdy.24178.

[25] C. Gálvez-Montón, M.T. Fernandez-Figueras, M. Martí, C. Soler-Botija, S. Roura, I. Perea-Gil, C. Prat-Vidal, A. Llucià-Valldeperas, Á. Raya, A. Bayes-Genis, Neoinnervation and neovascularization of acellular pericardial-derived scaffolds in myocardial infarcts, Stem Cell Res. Ther. 6 (2015) 1-7. doi:10.1186/s13287-015-0101-6.

[26] T.L. Criswell, B.T. Corona, Z. Wang, Y. Zhou, G. Niu, Y. Xu, G.J. Christ, S. Soker, The role of endothelial cells in myofiber differentiation and the vascularization and innervation of bioengineered muscle tissue in vivo., Biomaterials. 34 (2013) 140-149.

doi:10.1016/j.biomaterials.2012.09.045.

[27] R.B. Reinert, Q. Cai, J.-Y. Hong, J.L. Plank, K. Aamodt, N. Prasad, R. Aramandla, C. Dai, S.E. Levy, A. Pozzi, P.A. Labosky, C.V.E. Wright, M. Brissova, A.C. Powers, Vascular endothelial growth factor coordinates islet innervation via vascular scaffolding, Development. 141 (2014) 1480-1491. doi:10.1242/dev.098657.

[28] H.-Y. Wang, R.-H. Wei, S.-Z. Zhao, Evaluation of corneal cell growth on tissue engineering materials as artificial cornea scaffolds, Int. J. Ophthalmol. 6 (2013) 873-878. doi:10.3980/j.issn.2222-3959.2013.06.23.

[29] T. Kaully, K. Kaufman-francis, A. Lesman, S. Levenberg, Vascularization : The Conduit to Viable Engineered Tissues, in: P.C. Johnson, A.G. Mikos (Eds.), Adv. Tissue Eng. Angiogenes., Mary Ann Liebert, Inc., publishers, 2010.

[30] J. Rouwkema, N.C. Rivron, C.A. van Blitterswijk, Vascularization in tissue engineering, Trends Biotechnol. 26 (2016) 434-441. doi:10.1016/j.tibtech.2008.04.009.

[31] D. Richards, J. Jia, M. Yost, R. Markwald, Y. Mei, 3D Bioprinting for Vascularized Tissue Fabrication, Ann. Biomed. Eng. (2016) 1-16. doi:10.1007/s10439-016-1653-z.

[32] M.I. Santos, R.L. Reis, Vascularization in bone tissue engineering: physiology, current 
strategies, major hurdles and future challenges, Macromol. Biosci. 10 (2010) 12-27. doi:10.1002/mabi.200900107.

[33] C.K. Griffith, C. Miller, R.C. Sainson, J.W. Calvert, N.L. Jeon, C.C. Hughes, S.C. George, Diffusion limits of an in vitro thick prevascularized tissue, Tissue Eng. 11 (2005) 257-266. doi:10.1089/ten.2005.11.257.

[34] Y. Pang, K. Montagne, M. Shinohara, K. Komori, Y. Sakai, Liver tissue engineering based on aggregate assembly: efficient formation of endothelialized rat hepatocyte aggregates and their immobilization with biodegradable fibres, Biofabrication. 4 (2012) 45004. doi:10.1088/1758-5082/4/4/045004.

[35] J.W. Lee, Y. Choi, W. Yong, F. Pati, J. Shim, K.S. Kang, I.-H. Kang, J. Park, D.-W. Cho, Development of a 3D cell printed construct considering angiogenesis for liver tissue engineering, Biofabrication. 8 (2016) 15007. doi:10.1088/1758-5090/8/1/015007.

[36] M. Neufurth, X. Wang, E. Tolba, B. Dorweiler, H.C. Schröder, T. Link, B. Diehl-Seifert, W.E.G. Müller, Modular small diameter vascular grafts with bioactive functionalities, PLoS One. 10 (2015) 1-24. doi:10.1371/journal.pone.0133632.

[37] S. Pashneh-Tala, S. MacNeil, F. Claeyssens, The Tissue-Engineered Vascular GraftPast, Present, and Future, Tissue Eng. Part B Rev. 22 (2015) 68-100. doi:10.1089/ten.teb.2015.0100.

[38] M. Lovett, K. Lee, A. Edwards, D.L. Kaplan, Vascularization Strategies for Tissue Engineering, Tissue Eng. Part B Rev. 15 (2009) 353-370. 10.1089/ten.teb.2009.0085.

[39] J.C. Chung, D. Shum-Tim, Neovascularization in Tissue Engineering, Cells. 1 (2012) 1246-1260. doi:10.3390/cells1041246.

[40] M.W. Laschke, M.D. Menger, Vascularization in tissue engineering: Angiogenesis versus inosculation, Eur. Surg. Res. 48 (2012) 85-92. doi:10.1159/000336876.

[41] Z. Lokmic, G.M. Mitchell, Engineering the microcirculation., Tissue Eng. Part B. Rev. 14 (2008) 87-103. doi:10.1089/teb.2007.0299.

[42] J. V. Serbo, S. Gerecht, Vascular tissue engineering: biodegradable scaffold platforms to promote angiogenesis., Stem Cell Res. Ther. 4 (2013) 8. doi:10.1186/scrt156.

[43] S.B. Riemenschneider, D.J. Mattia, J.S. Wendel, J.A. Schaefer, L. Ye, P.A. Guzman, R.T. Tranquillo, Inosculation and perfusion of pre-vascularized tissue patches containing aligned human microvessels after myocardial infarction, Biomaterials. 97 (2016) 51-61. doi:10.1016/j.biomaterials.2016.04.031.

[44] J.E. Leslie-Barbick, J.E. Saik, D.J. Gould, M.E. Dickinson, J.L. West, The promotion of microvasculature formation in poly(ethylene glycol) diacrylate hydrogels by an immobilized VEGF-mimetic peptide, Biomaterials. 32 (2011) 5782-5789. doi:10.1016/j.biomaterials.2011.04.060.

[45] R. Sooppan, S.J. Paulsen, J. Han, A.H. Ta, P. Dinh, A.C. Gaffey, C. Venkataraman, A. Trubelja, G. Hung, J.S. Miller, P. Atluri, In Vivo Anastomosis and Perfusion of a ThreeDimensionally-Printed Construct Containing Microchannel Networks, Tissue Eng. Part C Methods. 22 (2015) 1-7. doi:10.1089/ten.tec.2015.0239.

[46] J. Baldwin, M. Antille, U. Bonda, E.M. De-Juan-Pardo, K. Khosrotehrani, S. Ivanovski, E.B. Petcu, D.W. Hutmacher, In vitro pre-vascularisation of tissue-engineered constructs A co-culture perspective, Vasc. Cell. 6 (2014) 1-16. doi:10.1186/2045-824X-6-13.

[47] V.K. Bajpai, S.T. Andreadis, Stem cell sources for vascular tissue engineering and regeneration., Tissue Eng. Part B. Rev. 18 (2012) 405-25.

doi:10.1089/ten.TEB.2011.0264. 
[48] A. Geevarghese, I.M. Herman, Pericyte-Endothelial Cross-Talk: Implications and Opportunities for Advanced Cellular Therapies, Transl. Res. 163 (2014) 296-306. doi:10.1016/j.trsl.2014.01.011.

[49] J. Rouwkema, A. Khademhosseini, Vascularization and Angiogenesis in Tissue Engineering: Beyond Creating Static Networks, Trends Biotechnol. 34 (2016) 733-745. doi:10.1016/j.tibtech.2016.03.002.

[50] A. Kumar, B. Starly, Large scale industrialized cell expansion: producing the critical raw material for biofabrication processes, Biofabrication. 7 (2015) 44103. doi:10.1088/17585090/7/4/044103.

[51] S. Yeasmin, J. Ceccarelli, M. Vigen, B. Carrion, A.J. Putnam, S.A. Tarle, D. Kaigler, Stem Cells Derived from Tooth Periodontal Ligament Enhance Functional Angiogenesis by Endothelial Cells, Tissue Eng. Part A. . 20 (2014) 1188-1196. doi:10.1089/ten.tea.2013.0512.

[52] Y. Amano, A. Nishiguchi, M. Matsusaki, H. Iseoka, S. Miyagawa, Y. Sawa, M. Seo, T. Yamaguchi, M. Akashi, Development of vascularized iPSC derived 3D-cardiomyocyte tissues by filtration Layer-by-Layer technique and their application for pharmaceutical assays, Acta Biomater. 33 (2016) 110-121. doi:10.1016/j.actbio.2016.01.033.

[53] D.G. Seifu, K. Mequanint, Fabrication of Vascular Tissue Engineering Scaffolds with Enhanced Oxygen Diffusivity and Cell Infiltration, J. Biomater. Tissue Eng. 2 (2012) 280-291. http://www.ingentaconnect.com/content/asp/jbte/2012/00000002/00000004/art00003.

[54] S.C. Baker, G. Rohman, J. Hinley, J. Stahlschmidt, N.R. Cameron, J. Southgate, Cellular integration and vascularisation promoted by a resorbable, particulate-leached, cross-linked poly(E-caprolactone) scaffold., Macromol. Biosci. 11 (2011) 618-27. doi:10.1002/mabi.201000415.

[55] W. Thein-Han, H.H.K. Xu, Prevascularization of a Gas-Foaming Macroporous Calcium Phosphate Cement Scaffold Via Coculture of Human Umbilical Vein Endothelial Cells and Osteoblasts, Tissue Eng. Part A. 19 (2013) 1675-1685. doi:10.1089/ten.tea.2012.0631.

[56] S. Singh, B.M. Wu, J.C.Y. Dunn, The enhancement of VEGF-mediated angiogenesis by polycaprolactone scaffolds with surface cross-linked heparin, Biomaterials. 32 (2011) 2059-2069. doi:10.1016/j.biomaterials.2010.11.038.

[57] T. Simón-Yarza, F.R. Formiga, E. Tamayo, B. Pelacho, F. Prosper, M.J. Blanco-Prieto, Vascular endothelial growth factor-delivery systems for cardiac repair: An overview, Theranostics. 2 (2012) 541-552. doi:10.7150/thno.3682.

[58] I.S. Park, S.-H. Kim, Y.H. Kim, I.H. Kim, S.H. Kim, A Collagen/Smooth Muscle CellIncorporated Elastic Scaffold for Tissue-Engineered Vascular Grafts, J. Biomater. Sci. Polym. Ed. 20 (2009) 1645-1660. doi:10.1163/156856208X386237.

[59] H.-Y. Mi, X. Jing, J. McNulty, M.R. Salick, X.-F. Peng, L.-S. Turng, Approaches to Fabricating Multiple-Layered Vascular Scaffolds Using Hybrid Electrospinning and Thermally Induced Phase Separation Methods, Ind. Eng. Chem. Res. 55 (2016) 882-892. doi:10.1021/acs.iecr.5b03462.

[60] R. Gauvin, T. Ahsan, D. Larouche, P. Lévesque, J. Dubé, F. a Auger, R.M. Nerem, L. Germain, A novel single-step self-assembly approach for the fabrication of tissueengineered vascular constructs., Tissue Eng. Part A. 16 (2010) 1737-1747. doi:10.1089/ten.tea.2009.0313. 
[61] A. Hasan, A. Memic, N. Annabi, M. Hossain, A. Paul, M.R. Dokmeci, F. Dehghani, A. Khademhosseini, Electrospun scaffolds for tissue engineering of vascular grafts, Acta Biomater. 10 (2014) 11-25. doi:10.1016/j.actbio.2013.08.022.

[62] W. Meyer, S. Engelhardt, E. Novosel, B. Elling, M. Wegener, H. Krüger, Soft Polymers for Building up Small and Smallest Blood Supplying Systems by Stereolithography, J. Funct. Biomater. 3 (2012) 257-268. doi:10.3390/jfb3020257.

[63] B. Huber, S. Engelhardt, W. Meyer, H. Krüger, A. Wenz, V. Schönhaar, G.E.M. Tovar, P.J. Kluger, K. Borchers, Blood-Vessel Mimicking Structures by Stereolithographic Fabrication of Small Porous Tubes Using Cytocompatible Polyacrylate Elastomers, Biofunctionalization and Endothelialization, J. Funct. Biomater. 7 (2016) 11. doi:10.3390/jfb7020011.

[64] A. Owida, R. Chen, S. Patel, Y. Morsi, X. Mo, Artery vessel fabrication using the combined fused deposition modeling and electrospinning techniques, Rapid Prototyp. J. 17 (2011) 37-44. doi:10.1108/13552541111098617.

[65] M. Centola, A. Rainer, C. Spadaccio, S. De Porcellinis, J.A. Genovese, M. Trombetta, Combining electrospinning and fused deposition modeling for the fabrication of a hybrid vascular graft, Biofabrication. 2 (2010) 14102. doi:10.1088/1758-5082/2/1/014102.

[66] S. Amensag, P.S. McFetridge, Rolling the Human Amnion to Engineer Laminated Vascular Tissues, Tissue Eng. Part C. Methods. 18 (2012) 903-912. doi:10.1089/ten.tec.2012.0119.

[67] J. An, J.E.M. Teoh, R. Suntornnond, C.K. Chua, Design and 3D Printing of Scaffolds and Tissues, Engineering. 1 (2015) 261-268. doi:10.15302/J-ENG-2015061.

[68] A.J. Melchiorri, J.P. Fisher, Bioprinting of Blood Vessels, in: A. Atala, J.J. Yoo (Eds.), Essentials 3D Biofabrication Transl., 2015: pp. 337-350. doi:10.1016/B978-0-12-8009727.00020-7.

[69] I.T. Ozbolat, Scaffold-Based or Scaffold-Free Bioprinting: Competing or Complementing Approaches?, J. Nanotechnol. Eng. Med. 6 (2015) 24701. doi:10.1115/1.4030414.

[70] K. Jakab, F. Marga, C. Norotte, K. Murphy, G. Vunjak-Novakovic, G. Forgacs, Tissue engineering by self-assembly and bio-printing of living cells, Biofabrication. 2 (2010) 22001. doi:10.1088/1758-5082/2/2/022001.

[71] P.A. Fleming, W.S. Argraves, C. Gentile, A. Neagu, G. Forgacs, C.J. Drake, Fusion of uniluminal vascular spheroids: a model for assembly of blood vessels, Dev. Dyn. 239 (2010) 398-406. doi:10.1002/dvdy.22161.

[72] M. Hospodiuk, K.K. Moncal, M. Dey, I.T. Ozbolat, Extrusion-Based Biofabrication in Tissue Engineering and Regenerative Medicine, in: A. Ovsianikov, J. Yoo, V. Mironov (Eds.), 3D Print. Biofabrication, Springer International Publishing, Cham, 2016: pp. 1-27. doi:10.1007/978-3-319-40498-1_10-1.

[73] A.-V. Do, A. Akkouch, B. Green, I. Ozbolat, A. Debabneh, S. Geary, A.K. Salem, Controlled and Sequential Delivery of Fluorophores from 3D Printed Alginate-PLGA Tubes, Ann. Biomed. Eng. (2016) 1-9. doi:10.1007/s10439-016-1648-9.

[74] N.E. Fedorovich, I. Swennen, J. Girones, L. Moroni, C.A. van Blitterswijk, E. Schacht, J. Alblas, W.J.A. Dhert, Evaluation of Photocrosslinked Lutrol Hydrogel for Tissue Printing Applications, Biomacromolecules. 10 (2009) 1689-1696. doi:10.1021/bm801463q.

[75] T. Jungst, W. Smolan, K. Schacht, T. Scheibel, J. Groll, Strategies and Molecular Design Criteria for 3D Printable Hydrogels, Chem. Rev. 116 (2016) 1496-1539. doi:10.1021/acs.chemrev.5b00303. 
[76] C.M. Smith, A.L. Stone, R.L. Parkhill, R.L. Stewart, M.W. Simpkins, A.M. Kachurin, W.L. Warren, S.K. Williams, Three-Dimensional BioAssembly Tool for Generating Viable Tissue-Engineered Constructs, Tissue Eng. 10 (2004) 1566-1576. doi:10.1089/ten.2004.10.1566.

[77] C.M. Smith, J.J. Christian, W.L. Warren, S.K. Williams, Characterizing Environmental Factors that Impact the Viability of Tissue-Engineered Constructs Fabricated by a DirectWrite Bioassembly Tool, Tissue Eng. 13 (2007) 373-383. doi:10.1089/ten.2006.0101.

[78] V. Mironov, V. Kasyanov, R.R. Markwald, Nanotechnology in vascular tissue engineering: from nanoscaffolding towards rapid vessel biofabrication., Trends Biotechnol. 26 (2008) 338-44. doi:10.1016/j.tibtech.2008.03.001.

[79] A. Panwar, L.P. Tan, Current Status of Bioinks for Micro-Extrusion-Based 3D Bioprinting, Molecules. 21 (2016) 685. doi:10.3390/molecules21060685.

[80] Shengjie Li, Zhuo Xiong, Xiaohong Wang, Yongnian Yan, Haixia Liu, Renji Zhang, Direct Fabrication of a Hybrid Cell/Hydrogel Construct by a Double-nozzle Assembling Technology, J. Bioact. Compat. Polym. 24 (2009) 249-265. doi:10.1177/0883911509104094.

[81] A. Skardal, J. Zhang, G.D. Prestwich, Bioprinting vessel-like constructs using hyaluronan hydrogels crosslinked with tetrahedral polyethylene glycol tetracrylates, Biomaterials. 31 (2010) 6173-6184. doi:10.1016/j.biomaterials.2010.04.045.

[82] A. Skardal, J. Zhang, L. Mccoard, X. Xu, S. Oottamasathien, G.D. Prestwich, Photocrosslinkable Hyaluronan-Gelatin Hydrogels for Two-Step Bioprinting, Tissue Eng. Part A. 16 (2010) 2675-2685. doi:10.1089/ten.tea.2009.0798.

[83] E.Y.S. Tan, W.Y. Yeong, Concentric bioprinting of alginate-based tubular constructs using multi-nozzle extrusion-based technique, Int. J. Bioprinting. 1 (2015) 49-56. doi:10.18063/IJB.2015.01.003.

[84] T.J. Hinton, Q. Jallerat, R.N. Palchesko, J.H. Park, M.S. Grodzicki, H.-J. Shue, M.H. Ramadan, A.R. Hudson, A.W. Feinberg, Three-dimensional printing of complex biological structures by freeform reversible embedding of suspended hydrogels, Sci. Adv. 1 (2015). doi:10.1126/sciadv.1500758.

[85] H. Onoe, S. Takeuchi, Cell-laden microfibers for bottom-up tissue engineering, Drug Discov. Today. 20 (2015) 236-246. doi:10.1016/j.drudis.2014.10.018.

[86] H. Onoe, T. Okitsu, A. Itou, M. Kato-Negishi, R. Gojo, D. Kiriya, K. Sato, S. Miura, S. Iwanaga, K. Kuribayashi-Shigetomi, Y.T. Matsunaga, Y. Shimoyama, S. Takeuchi, Metre-long cell-laden microfibres exhibit tissue morphologies and functions, Nat Mater. 12 (2013) 584-590. doi:10.1038/nmat3606.

[87] P. Sher, S.M. Oliveira, J. Borges, J.F. Mano, Assembly of cell-laden hydrogel fiber into non-liquefied and liquefied 3D spiral constructs by perfusion-based layer-by-layer technique, Biofabrication. 7 (2015). doi:10.1088/1758-5090/7/1/011001.

[88] Y. Zhang, Y. Yu, I.T. Ozbolat, Direct Bioprinting of Vessel-Like Tubular Microfluidic Channels, J. Nanotechnol. Eng. Med. 4 (2013) 210011-210017. doi:10.1115/1.4024398.

[89] Y. Yu, Y. Zhang, J.A. Martin, I.T. Ozbolat, Evaluation of Cell Viability and Functionality in Vessel-like Bioprintable Cell-Laden Tubular Channels, J. Biomech. Eng. 135 (2013) 19. doi:10.1115/1.4024575.

[90] Y. Zhang, 3D bioprinting of vasculature network for tissue engineering, University of Iowa, 2014. http://ir.uiowa.edu/etd/4801.

[91] Y. Zhang, Y. Yu, A. Akkouch, A. Dababneh, F. Dolati, I.T. Ozbolat, In vitro study of 
directly bioprinted perfusable vasculature conduits, Biomater. Sci. 3 (2015) 134-143. doi:10.1039/C4BM00234B.

[92] F. Dolati, Y. Yu, Y. Zhang, A.M. De Jesus, E.A. Sander, I.T. Ozbolat, In vitro evaluation of carbon-nanotube- reinforced bioprintable vascular conduits, Nanotechnology. 25 (2014) 145101-10. doi:10.1088/0957-4484/25/14/145101.

[93] Q. Gao, Y. He, J. Fu, A. Liu, L. Ma, Coaxial nozzle-assisted 3D bioprinting with built-in microchannels for nutrients delivery, Biomaterials. 61 (2015) 203-215. doi:10.1016/j.biomaterials.2015.05.031.

[94] R. Attalla, C. Ling, P. Selvaganapathy, Fabrication and characterization of gels with integrated channels using 3D printing with microfluidic nozzle for tissue engineering applications, Biomed. Microdevices. 18 (2016) 1-12. doi:10.1007/s10544-016-0042-6.

[95] R. Attalla, P.R. Selvaganapathy, 3d printing of gels with integrated vascular channels for cell culture using a microfluidic printhead, in: 18th Int. Conf. Miniaturized Syst. Chem. Life Sci., San Antonio, Texas, USA, 2014: pp. 479-481.

[96] P.R. Selvaganapathy, R. Attala, Microfluidic vascular channels in gels using commercial 3D printers, in: B.L. Gray;, H. Becker (Eds.), Proc. SPIE 9705, Microfluid. BioMEMS, Med. Microsystems XIV, 97050J, San Francisco, California, United States, 2016: pp. 3-4. doi:10.1117/12.2218401.

[97] W. Jia, P.S. Gungor-Ozkerim, Y.S. Zhang, K. Yue, K. Zhu, W. Liu, Q. Pi, B. Byambaa, M.R. Dokmeci, S.R. Shin, A. Khademhosseini, Direct 3D bioprinting of perfusable vascular constructs using a blend bioink, Biomaterials. 106 (2016) 58-68. doi:10.1016/j.biomaterials.2016.07.038.

[98] L.E. Bertassoni, M. Cecconi, V. Manoharan, M. Nikkhah, J. Hjortnaes, A.L. Cristino, G. Barabaschi, D. Demarchi, M.R. Dokmeci, Y. Yang, A. Khademhosseini, Hydrogel bioprinted microchannel networks for vascularization of tissue engineering constructs, Lab Chip. 14 (2014) 2202-2211. doi:10.1039/c4lc00030g.

[99] Y.S. Zhang, F. Davoudi, P. Walch, A. Manbachi, X. Luo, V. Dell'Erba, A.K. Miri, H. Albadawi, A. Arneri, X. Li, X. Wang, M.R. Dokmeci, A. Khademhosseini, R. Oklu, Bioprinted thrombosis-on-a-chip, Lab Chip. 16 (2016) 4097-4105. doi:10.1039/C6LC00380J.

[100] S. Wüst, R. Muller, S. Hoffman, 3D Bioprinting of complex channels - Effects of material, orientation, geometry, and cell embedding, J. Biomed. Mater. Res. Part A. 103 (2015) 2558-2570. doi:10.1002/jbm.a.35393.

[101] J. Hendriks, C. Willem Visser, S. Henke, J. Leijten, D.B.F. Saris, C. Sun, D. Lohse, M. Karperien, Optimizing cell viability in droplet-based cell deposition, Sci. Rep. 5 (2015) 11304. doi:10.1038/srep11304.

[102] A.B. Dababneh, I.T. Ozbolat, Bioprinting Technology: A Current State-of-the-Art Review, J. Manuf. Sci. Eng. 136 (2014) 61016. doi:10.1115/1.4028512.

[103] A. Munaz, R.K. Vadivelu, J. St. John, M. Barton, H. Kamble, N.-T. Nguyen, Threedimensional printing of biological matters, J. Sci. Adv. Mater. Devices. 1 (2016) 1-17. doi:10.1016/j.jsamd.2016.04.001.

[104] S.W. Hock, D.A. Johnson, M.A. Van Veen, Print quality optimization for a color ink-jet printer by using a larger nozzle for the black ink only, US5521622, 1996.

[105] X. Cui, T. Boland, D.D. D'Lima, Martin K. Lotz, Thermal Inkjet Printing in Tissue Engineering and Regenerative Medicine, Recent Pat Ents Drug Deliv. Formul. 6 (2012) 149-155. doi:10.2174/187221112800672949. 
[106] K.R. Hudson, P.B. Cowan, J.S. Gondek, Ink drop volume variance compensation for inkjet printing, US Patent No. 6042211, 2000.

[107] J. de Jong, G. de Bruin, H. Reinten, M. van den Berg, H. Wijshoff, M. Versluis, D. Lohse, Air entrapment in piezo-driven inkjet printheads, J. Acoust. Soc. Am. 120 (2006). doi:10.1121/1.2216560.

[108] V. Tran, X. Wen, 4 - Rapid prototyping technologies for tissue regeneration, in: Rapid Prototyp. Biomater., 2014: pp. 97-155. doi:10.1533/9780857097217.97.

[109] I.T. Ozbolat, 3D Bioprinting: Fundamentals, Principles and Applications, 2016, Elsevier.

[110] F.T. Zohora, A. Yousuf, M. Anwarul, A.Y.M.A. Azim, Inkjet printing : an emerging technology for 3d tissue or organ printing, Eur. Sci. J. 10 (2014) 339-352.

[111] C. Xu, K. Christensen, Z. Zhang, Y. Huang, J. Fu, R.R. Markwald, Predictive compensation-enabled horizontal inkjet printing of alginate tubular constructs, Manuf. Lett. 1 (2013) 28-32. doi:10.1016/j.mfglet.2013.09.003.

[112] P. Kesari, T. Xu, T. Boland, Layer-by-layer printing of cells and its application to tissue engineering, MRS Online Proc. Libr. Arch. 845 (2004) AA4.5 (7 pages). doi:https://doi.org/10.1557/PROC-845-AA4.5.

[113] T. Boland, X. Tao, B.J. Damon, B. Manley, P. Kesari, S. Jalota, S. Bhaduri, Drop-ondemand printing of cells and materials for designer tissue constructs, Mater. Sci. Eng. C. 27 (2007) 372-376. doi:10.1016/j.msec.2006.05.047.

[114] X. Cui, T. Boland, Human microvasculature fabrication using thermal inkjet printing technology, Biomaterials. 30 (2009) 6221-6227. doi:10.1016/j.biomaterials.2009.07.056.

[115] K. Arai, S. Iwanaga, H. Toda, C. Genci, Y. Nishiyama, M. Nakamura, Three-dimensional inkjet biofabrication based on designed images, Biofabrication. 3 (2011) 34113. doi:10.1088/1758-5082/3/3/034113.

[116] M. Nakamura, A. Kobayashi, F. Takagi, A. Watanabe, Y. Hiruma, K. Ohuchi, Y. Iwasaki, M. Horie, I. Morita, Takatani, Biocompatible inkjet printing technique for designed seeding of individual living cells, Tissue Eng. 11 (2005) 1658-1666. doi:10.1089/ten.2005.11.1658.

[117] M. Nakamura, T.A. Mir, K. Arai, S. Ito, T. Yoshida, S. Iwanaga, H. Kitano, C. Obara, T. Nikaido, Bioprinting with pre-cultured cellular constructs towards tissue engineering of hierarchical tissues, Int. J. Bioprinting. 1 (2015). doi:http://dx.doi.org/10.18063/IJB.2015.01.007.

[118] M. Nakamura, Y. Nishiyama, C. Henmi, S. Iwanaga, H. Nakagawa, K. Yamaguchi, K. Akita, S. Mochizuki, K. Takiura, Ink jet three-dimensional digital fabrication for biological tissue manufacturing: analysis of alginate microgel beads produced by ink jet droplets for three dimensional tissue fabrication, J Imaging Sci Technol. 52 (2008) 602011-60201-6. doi:10.2352/J.ImagingSci.Technol.(2008)52:6(060201).

[119] C. Xu, Inkjet printing of three- dimensional vascular-like constructs from cell suspensions, Clemson Univertsity, 2014.

[120] C. Xu, Z. Zhang, K. Christensen, Y. Huang, J. Fu, R.R. Markwald, Freeform Vertical and Horizontal Fabrication of Alginate-Based Vascular-Like Tubular Constructs Using Inkjetting, J. Manuf. Sci. Eng. 136 (2014) 61020. http://dx.doi.org/10.1115/1.4028578.

[121] C. Xu, M. Zhang, Y. Huang, A. Ogale, J. Fu, R.R. Markwald, Study of Droplet Formation Process during Drop-on-Demand Inkjetting of Living Cell-Laden Bioink, Langmuir. 30 (2014) 9130-9138. doi:10.1021/la501430x.

[122] C. Xu, W. Chai, Y. Huang, R.R. Markwald, Scaffold--free inkjet printing of 
three-dimensional zigzag cellular tubes, Biotechnol. Bioeng. 109 (2012) 3152-3160. doi:10.1002/bit.24591/full.

[123] K. Christensen, C. Xu, W. Chai, Z. Zhang, J. Fu, Y. Huang, Freeform inkjet printing of cellular structures with bifurcations, Biotechnol. Bioeng. 112 (2015) 1047-1055. doi:10.1002/bit.25501/full.

[124] A. Blaeser, D.F. Duarte Campos, M. Weber, S. Neuss, B. Theek, H. Fischer, W. JahnenDechent, Biofabrication Under Fluorocarbon: A Novel Freeform Fabrication Technique to Generate High Aspect Ratio Tissue-Engineered Constructs, Biores. Open Access. 2 (2013) 374-384. doi:10.1089/biores.2013.0031.

[125] H.N. Chia, B.M. Wu, Recent advances in 3D printing of biomaterials, J. Biol. Eng. 9 (2015) 1-14. doi:10.1186/s13036-015-0001-4.

[126] D.F. Duarte Campos, A. Blaeser, M. Weber, J. Jäkel, S. Neuss, W. Jahnen-Dechent, H. Fischer, Three-dimensional printing of stem cell-laden hydrogels submerged in a hydrophobic high-density fluid, Biofabrication. 5 (2013) 15003. doi:10.1088/17585082/5/1/015003.

[127] N.A. Sears, D.R. Seshadri, P.S. Dhavalikar, E. Cosgriff-Hernandez, A Review of ThreeDimensional Printing in Tissue Engineering, Tissue Eng. Part B Rev. (2016). doi:10.1089/ten.teb.2015.0464.

[128] D.F. Duarte Campos, A. Blaeser, A. Korsten, S. Neuss, J. Jäkel, M. Vogt, H. Fischer, The Stiffness and Structure of Three-Dimensional Printed Hydrogels Direct the Differentiation of Mesenchymal Stromal Cells Toward Adipogenic and Osteogenic Lineages, Tissue Eng. Part A. 21 (2014) 740-756. doi:10.1089/ten.tea.2014.0231.

[129] D.F. Duarte Campos, A. Blaeser, K. Buellesbach, K.S. Sen, W. Xun, W. Tillmann, H. Fischer, Bioprinting Organotypic Hydrogels with Improved Mesenchymal Stem Cell Remodeling and Mineralization Properties for Bone Tissue Engineering, Adv. Healthc. Mater. 5 (2016) 1336-1345. doi:10.1002/adhm.201501033.

[130] V.K. Lee, D.Y. Kim, H. Ngo, Y. Lee, L. Seo, S. Yoo, P.A. Vincent, G. Dai, Creating perfused functional vascular channels using 3D bio-printing technology, Biomaterials. 35 (2014) 8092-8102. doi:10.1016/j.biomaterials.2014.05.083.

[131] J. Bohandy, B.F. Kim, F.J. Adrian, Metal deposition from a supported metal film using an excimer laser, J. Appl. Phys. 60 (1986) 1538-1539. doi:10.1063/1.337287.

[132] N.T. Kattamis, P.E. Purnick, R. Weiss, C.B. Arnold, Thick film laser induced forward transfer for deposition of thermally and mechanically sensitive materials, Appl. Phys. Lett. 91 (2007). doi:10.1063/1.2799877.

[133] M. Duocastella, J.M. Fernández-Pradas, J. Domínguez, P. Serra, J.L. Morenza, Printing biological solutions through laser-induced forward transfer, Appl. Phys. A. 93 (2008) 941-945. doi:10.1007/s00339-008-4741-6.

[134] M. Duocastella, Laser-induced Forward Transfer of Liquids for Miniaturized Biosensors Preparation, J. Laser Micro/Nanoengineering. 3 (2008) 1-4. doi:10.2961/jlmn.2008.01.0001.

[135] R. Devillard, E. Pagès, M.M. Correa, V. Kériquel, M. Rémy, J. Kalisky, M. Ali, B. Guillotin, F. Guillemot, Chapter 9 - Cell Patterning by Laser-Assisted Bioprinting, in: Methods Cell Biol., 2014: pp. 159-174. doi:10.1016/B978-0-12-416742-1.00009-3.

[136] H. Desrus, B. Chassagne, F. Moizan, R. Devillard, S. Petit, R. Kling, S. Catros, Effective parameters for film-free femtosecond laser assisted bioprinting, Appl. Opt. 55 (2016) 3879-3886. doi:10.1364/AO.55.003879. 
[137] B.R. Ringeisen, J.A. Barron, D. Young, C.M. Othon, D. Ladoucuer, P.K. Wu, B.J. Spargo, Laser Printing Cells BT - Virtual Prototyping \& Bio Manufacturing in Medical Applications, in: B. Bidanda, P. Bártolo (Eds.), Springer US, Boston, MA, 2008: pp. 207228. doi:10.1007/978-0-387-68831-2_10.

[138] M. Gruene, C. Unger, L. Koch, A. Deiwick, B. Chichkov, Dispensing pico to nanolitre of a natural hydrogel by laser-assisted bioprinting, Biomed. Eng. Online. 10 (2011) 19. doi:10.1186/1475-925X-10-19.

[139] L. Koch, M. Gruene, C. Unger, B. Chichkov, Laser assisted cell printing., Curr. Pharm. Biotechnol. 14 (2013) 91-7. doi:10.2174/138920113804805368.

[140] N. Mehrban, G.Z. Teoh, M.A. Birchall, 3D bioprinting for tissue engineering: Stem cells in hydrogels, Int. J. Bioprinting. 2 (2016). doi:10.18063/IJB.2016.01.006.

[141] R.F. Pereira, P.J. Bártolo, 3D Photo-Fabrication for Tissue Engineering and Drug Delivery, Engineering. 1 (2015) 090-112. doi:10.15302/J-ENG-2015015.

[142] A. Selimis, V. Mironov, M. Farsari, Direct laser writing: Principles and materials for scaffold 3D printing, Microelectron. Eng. 132 (2015) 83-89. doi:10.1016/j.mee.2014.10.001.

[143] P.K. Wu, B.R. Ringeisen, Development of human umbilical vein endothelial cell (HUVEC) and human umbilical vein smooth muscle cell (HUVSMC) branch/stem structures on hydrogel layers via biological laser printing (BioLP), Biofabrication. 2 (2010) 14111. doi:10.1088/1758-5082/2/1/014111.

[144] R.K. Pirlo, P. Wu, J. Liu, B. Ringeisen, PLGA/hydrogel biopapers as a stackable substrate for printing HUVEC networks via BioLP ${ }^{\mathrm{TM}}$, Biotechnol. Bioeng. 109 (2012) 262-273. doi:10.1002/bit.23295.

[145] R. Xiong, Z. Zhang, W. Chai, Y. Huang, D.B. Chrisey, Freeform drop-on-demand laser printing of 3D alginate and cellular constructs, Biofabrication. 7 (2015) 45011. doi:10.1088/1758-5090/7/4/045011.

[146] J.A. Barron, P. Wu, H.D. Ladouceur, B.R. Ringeisen, Biological laser printing: a novel technique for creating heterogeneous 3-dimensional cell patterns, Biomed. Microdevices. 6 (2004) 139-147. doi:10.1023/B:BMMD.0000031751.67267.9f.

[147] A. Ovsianikov, M. Gruene, M. Pflaum, L. Koch, F. Maiorana, M. Wilhelmi, A. Haverich, B. Chichkov, Laser printing of cells into 3D scaffolds, Biofabrication. 2 (2010) 14104. doi:10.1088/1758-5082/2/1/014104.

[148] R. Gaebel, N. Ma, J. Liu, J. Guan, L. Koch, C. Klopsch, M. Gruene, A. Toelk, W. Wang, P. Mark, F. Wang, B. Chichkov, W. Li, G. Steinhoff, Patterning human stem cells and endothelial cells with laser printing for cardiac regeneration., Biomaterials. 32 (2011) 9218-30. doi:10.1016/j.biomaterials.2011.08.071.

[149] K.C. Hribar, K. Meggs, J. Liu, W. Zhu, X. Qu, S. Chen, Three-dimensional direct cell patterning in collagen hydrogels with near-infrared femtosecond laser, Sci. Rep. 5 (2015) 17203. doi:10.1038/srep17203.

[150] K.C. Hribar, P. Soman, J. Warner, P. Chung, S. Chen, Light-assisted direct-write of 3D functional biomaterials, Lab Chip. 14 (2014) 268-275. doi:10.1039/c31c50634g.

[151] T.Q. Huang, X. Qu, J. Liu, S. Chen, 3D printing of biomimetic microstructures for cancer cell migration, Biomed. Microdevices. 16 (2014) 127-132. doi:10.1007/s10544-013-98126.

[152] R. Langer, J.P. Vacanti, Tissue Engineering, Science. 260 (1993) 920-926. doi:10.1126/science.8493529. 
[153] S. Shojaie, L. Ermini, C. Ackerley, J. Wang, S. Chin, B. Yeganeh, M. Bilodeau, M. Sambi, I. Rogers, J. Rossant, C.E. Bear, M. Post, Acellular Lung Scaffolds Direct Differentiation of Endoderm to Functional Airway Epithelial Cells: Requirement of Matrix-Bound HS Proteoglycans, Stem Cell Reports. 4 (2015) 419-430. doi:10.1016/j.stemcr.2015.01.004.

[154] M.J. Webber, O.F. Khan, S.A. Sydlik, B.C. Tang, R. Langer, A Perspective on the Clinical Translation of Scaffolds for Tissue Engineering, Ann. Biomed. Eng. 43 (2015) 641-656. doi:10.1007/s10439-014-1104-7.

[155] V. Catto, S. Farè, G. Freddi, M.C. Tanzi, Vascular Tissue Engineering: Recent Advances in Small Diameter Blood Vessel Regeneration Title, ISRN Vasc. Med. 923030 (2014) 27. doi:10.1155/2014/923030.

[156] M. Deutsch, J. Meinhart, P. Zilla, N. Howanietz, M. Gorlitzer, A. Froeschl, A. Stuempflen, D. Bezuidenhout, M. Grabenwoeger, Long-term experience in autologous in vitro endothelialization of infrainguinal ePTFE grafts, J. Vasc. Surg. 49 (2009) 352-362. doi:10.1016/j.jvs.2008.08.101.

[157] S.L.M. Dahl, C. Rhim, Y.C. Song, L.E. Niklason, Mechanical Properties and Compositions of Tissue Engineered and Native Arteries, Ann. Biomed. Eng. 35 (2007) 348-355. doi:10.1007/s10439-006-9226-1.

[158] N. Thottappillil, P.D. Nair, Scaffolds in vascular regeneration: current status, Vasc. Health Risk Manag. 11 (2015) 79-91. doi:10.2147/VHRM.S50536.

[159] C.A. Czajka, A.N. Mehesz, T.C. Trusk, M.J. Yost, C.J. Drake, Scaffold-Free Tissue Engineering: Organization of the Tissue Cytoskeleton and Its Effects on Tissue Shape, Ann. Biomed. Eng. 42 (2014) 1049-1061. doi:10.1007/s10439-014-0986-8.

[160] Y. Jung, H. Ji, Z. Chen, H. Fai Chan, L. Atchison, B. Klitzman, G. Truskey, K.W. Leong, Scaffold-free, Human Mesenchymal Stem Cell-Based Tissue Engineered Blood Vessels, Sci. Rep. 5 (2015) 15116. doi:10.1038/srep15116.

[161] Y. Tan, D.J. Richards, T.C. Trusk, R.P. Visconti, M.J. Yost, M.S. Kindy, C.J. Drake, W.S. Argraves, R.R. Markwald, Y. Mei, 3D Printing Facilitated Scaffold-free Tissue Unit Fabrication, Biofabrication. 6 (2014) 24111. doi:10.1088/1758-5082/6/2/024111.

[162] J.M. Kelm, V. Djonov, L.M. Ittne, D. Fluri, W. Born, S.P. Hoerstrup, Martin Fussenegger, Design of Custom-Shaped Vascularized Tissues Using Microtissue Spheroids as Minimal Building Units, Tissue Eng. 12 (2006) 2151-2160. doi:10.1089/ten.2006.12.2151.

[163] C. Norotte, F.S. Marga, L.E. Niklason, G. Forgacs, Scaffold-free vascular tissue engineering using bioprinting, Biomaterials. 30 (2009) 5910-5917. doi:10.1016/j.biomaterials.2009.06.034.

[164] C. Kucukgul, B. Ozler, H.E. Karakas, D. Gozuacik, B. Koc, 3D hybrid bioprinting of macrovascular structures, Procedia Eng. 59 (2013) 183-192. doi:10.1016/j.proeng.2013.05.109.

[165] C. Kucukgul, S.B. Ozler, I. Inci, E. Karakas, S. Irmak, D. Gozuacik, A. Taralp, B. Koc, 3D bioprinting of biomimetic aortic vascular constructs with selfsupporting cells, Biotechnol. Bioeng. 112 (2015) 811-821. doi:10.1002/bit.25493.

[166] R.P. Visconti, V. Kasyanov, C. Gentile, J. Zhang, R.R. Markwald, V. Mironov, Towards organ printing: engineering an intra-organ branched vascular tree, Expert Opin. Biol. Ther. 10 (2010) 409-420. doi:10.1517/14712590903563352.

[167] J. Visser, B. Peters, T.J. Burger, J. Boomstra, W.J.A. Dhert, F.P.W. Melchels, J. Malda, Biofabrication of multi-material anatomically shaped tissue constructs, Biofabrication. 5 
(2013) 35007. doi:10.1088/1758-5082/5/3/035007.

[168] J.S. Miller, K.R. Stevens, M.T. Yang, B.M. Baker, D.-H.T. Nguyen, D.M. Cohen, E. Toro, A.A. Chen, P.A. Galie, X. Yu, R. Chaturvedi, S.N. Bhatia, C.S. Chen, Rapid casting of patterned vascular networks for perfusable engineered 3D tissues, Nat. Mater. 11 (2012) 768-774. doi:10.1038/nmat3357.

[169] D.B. Kolesky, R.L. Truby, A.S. Gladman, T.A. Busbee, K.A. Homan, J.A. Lewis, 3D Bioprinting of Vascularized, Heterogeneous Cell-Laden Tissue Constructs, Adv. Mater. 26 (2014) 3124-3130. doi:10.1002/adma.201305506.

[170] D.B. Kolesky, K.A. Homan, M.A. Skylar-scott, J.A. Lewis, Three-dimensional bioprinting of thick vascularized tissues, Proc. Natl. Acad. Sci. Am. 113 (2016) 31793184. doi:10.1073/pnas.1521342113.

[171] H. Kang, S.J. Lee, I.K. Ko, C. Kengla, J.J. Yoo, A. Atala, A 3D bioprinting system to produce human-scale tissue constructs with structural integrity, Nat. Biotechnol. 34 (2016) 312-319. doi:10.1038/nbt.3413.

[172] A. Akkouch, Y. Yu, I.T. Ozbolat, Microfabrication of scaffold-free tissue strands for three-dimensional tissue engineering, Biofabrication. 7 (2015) 31002. doi:10.1088/17585090/7/3/031002.

[173] Y. Yu, I.T. Ozbolat, Tissue strands as bioink for scale-up organ printing, 2014 36th Annu. Int. Conf. IEEE Eng. Med. Biol. Soc. (2014) 1428-1431. doi:10.1109/EMBC.2014.6943868.

[174] Y. Yu, K.K. Moncal, J. Li, W. Peng, I. Rivero, J.A. Martin, I.T. Ozbolat, Threedimensional bioprinting using self-assembling scalable scaffold-free "tissue strands" as a new bioink, Sci. Rep. 6 (2016) 28714. doi:10.1038/srep28714.

[175] I.T. Ozbolat, H. Chen, Y. Yu, Development of " Multi-arm Bioprinter " for hybrid biofabrication of tissue engineering constructs, Robot. Comput. Integr. Manuf. 30 (2014) 295-304. doi:10.1016/j.rcim.2013.10.005.

[176] Y. Yu, Y. Zhang, I.T. Ozbolat, A Hybrid Bioprinting Approach for Scale-Up Tissue Fabrication, J. Manuf. Sci. Eng. 136 (2014) 61013-1. doi:10.1115/1.4028511.

[177] N.E. Fedorovich, H.M. Wijnberg, W.J.A. Dhert, J. Alblas, Distinct Tissue Formation by Heterogeneous Printing of Osteo- and Endothelial Progenitor Cells, Tissue Eng. Part A. 17 (2011) 2113-2121. doi:10.1089/ten.tea.2011.0019.

[178] C.C. Chang, L. Krishnan, S.S. Nunes, K.H. Church, L.T. Edgar, E.D. Boland, J. a Weiss, S.K. Williams, B. James, Determinants of Microvascular Network Topologies in Implanted Neovasculatures, Arter. Thromb Vasc Biol. 32 (2012) 5-14. doi:10.1161/ATVBAHA.111.238725.Determinants.

[179] K. Jakab, A. Neagu, V. Mironov, R.R. Markwald, G. Forgacs, Engineering biological structures of prescribed shape using self-assembling multicellular systems., Proc. Natl. Acad. Sci. U. S. A. 101 (2004) 2864-9. doi:10.1073/pnas.0400164101.

[180] V. Mironov, V. Kasyanov, R.R. Markwald, Organ printing: from bioprinter to organ biofabrication line, Curr. Opin. Biotechnol. 22 (2011) 667-673. doi:10.1016/j.copbio.2011.02.006.

[181] L.E. Bertassoni, J.C. Cardoso, V. Manoharan, A.L. Cristino, N.S. Bhise, W.A. Araujo, P. Zorlutuna, N.E. Vrana, A.M. Ghaemmaghami, M.R. Dokmeci, A. Khademhosseini, Direct-write bioprinting of cell-laden methacrylated gelatin hydrogels, Biofabrication. 6 (2014) 24105. doi:10.1088/1758-5082/6/2/024105.

[182] W. Wu, A. DeConinck, J.A. Lewis, Omnidirectional Printing of 3D Microvascular 
Networks, Adv. Mater. 23 (2011) H178-H183. doi:10.1002/adma.201004625.

[183] S. Bersini, J.S. Jeon, G. Dubini, C. Arrigoni, S. Chung, J.L. Charest, M. Moretti, R.D. Kamm, A microfluidic 3D in vitro model for specificity of breast cancer metastasis to bone, Biomaterials. 35 (2014) 2454-2461. doi:10.1016/j.biomaterials.2013.11.050.

[184] I.T. Ozbolat, W. Peng, V. Ozbolat, Application areas of 3D bioprinting, Drug Discov. Today. (2016). doi:10.1016/j.drudis.2016.04.006.

[185] J. Jang, H.-G. Yi, D.-W. Cho, 3D Printed Tissue Models: Present and Future, ACS Biomater. Sci. Eng. (2016). doi:10.1021/acsbiomaterials.6b00129.

[186] P. Calvert, Inkjet Printing for Materials and Devices, Chem. Mater. 13 (2001) 3299-3305. doi:10.1021/cm0101632.

[187] S. Tasoglu, U. Demirci, Bioprinting for stem cell research, Trends Biotechnol. 31 (2013) 10-19. doi:10.1016/j.tibtech.2012.10.005.

[188] C.G. Williams, A.N. Malik, T.K. Kim, P.N. Manson, J.H. Elisseeff, Variable cytocompatibility of six cell lines with photoinitiators used for polymerizing hydrogels and cell encapsulation, Biomaterials. 26 (2005) 1211-1218. doi:10.1016/j.biomaterials.2004.04.024.

[189] Y. Lu, S. Chen, Computer-Aided Tissue Engineering, in: A.K.M. Liebschner (Ed.), Humana Press, Totowa, NJ, 2012: pp. 289-302. doi:10.1007/978-1-61779-764-4_17.

[190] N.E. Fedorovich, M.H. Oudshoorn, D. van Geemen, W.E. Hennink, J. Alblas, W.J.A. Dhert, The effect of photopolymerization on stem cells embedded in hydrogels, Biomaterials. 30 (2009) 344-353. doi:10.1016/j.biomaterials.2008.09.037.

[191] C. Mandrycky, Z. Wang, K. Kim, D.-H. Kim, 3D Bioprinting for Engineering Complex Tissues, Biotechnol. Adv. 34 (2016) 422-434. doi:10.1016/j.biotechadv.2015.12.011.

[192] S. Wüst, R. Müller, S. Hofmann, Controlled Positioning of Cells in BiomaterialsApproaches Towards 3D Tissue Printing, J. Funct. Biomater. 2 (2011) 119-154. doi:10.3390/jfb2030119.

[193] F. Guillemot, A. Souquet, S. Catros, B. Guillotin, Laser-assisted cell printing: principle, physical parameters versus cell fate and perspectives in tissue engineering, Nanomedicine. 5 (2010) 507-515. doi:10.2217/nnm.10.14.

[194] M. Gruene, A. Deiwick, L. Koch, S. Schlie, C. Unger, N. Hofmann, I. Bernemann, B. Glasmacher, B. Chichkov, Laser Printing of Stem Cells for Biofabrication of ScaffoldFree Autologous Grafts, Tissue Eng. Part C Methods. 17 (2010) 79-87. doi:10.1089/ten.tec.2010.0359.

[195] V.K. Lee, A. Dias, M.S. Ozturk, K. Chen, B. Tricomi, D.T. Corr, X. Intes, G. Dai, 3D Bioprinting and 3D Imaging for Stem Cell Engineering, in: K. Turksen (Ed.), Bioprinting Regen. Med. Stem Cell Biol. Regen. Med., Springer International Publishing, Switzerland, 2015: pp. 33-43. doi:10.1007/978-3-319-21386-6.

[196] M. Itoh, K. Nakayama, R. Noguchi, K. Kamohara, K. Furukawa, K. Uchihashi, S. Toda, J. Oyama, K. Node, S. Morita, Scaffold-Free Tubular Tissues Created by a Bio-3D Printer Undergo Remodeling and Endothelialization when Implanted in Rat Aortae, PLoS One. 10 (2015) e0136681. doi:10.1088/1758-5082/6/2/024105.

[197] S.G. Dennis, T. Trusk, D. Richards, J. Jia, Y. Tan, Y. Mei, S. Fann, R. Markwald, M. Yost, Viability of Bioprinted Cellular Constructs Using a Three Dispenser Cartesian Printer, J. Vis. Exp. (2015) 10.3791/53156. doi:10.3791/53156.

[198] C.A. Wilkens, C.J. Rivet, T.L. Akentjew, J. Alverio, M. Khoury, J.P. Acevedo, Layer-bylayer approach for a uniformed fabrication of a cell patterned vessel-like construct, 
Biofabrication. 9 (2017) 15001. doi:10.1088/1758-5090/9/1/015001.

[199] B. Gao, Q. Yang, X. Zhao, G. Jin, Y. Ma, F. Xu, 4D Bioprinting for Biomedical Applications, Trends Biotechnol. (2016). doi:10.1016/j.tibtech.2016.03.004.

[200] J. An, C.K. Chua, V. Mironov, A perspective on 4D bioprinting, Int. J. Bioprinting. 2 (2016) 3-5. doi:10.18063/IJB.2016.01.003. 


\section{Figure Captions}

Fig. 1. A general schematic of 3D bioprinting for vascularized tissue biofabrication (bioprinter image was obtained with permission from [9]). Bioprinting enables fabrication of vascularized tissues through layer-by-layer deposition of bioink solutions that can be polymerized through ionic-, enzymatic-, or photopolymerization-based crosslinking mechanisms. A support material is required to hold the entire construct in place until sufficient tissue maturation is achieved. Ideally, engineered vascular tissue should mimic the native counterpart, which is composed of three major layers including tunica external, tunica media, and tunica internal.

Fig. 2. Bioprinting of vascular constructs using direct extrusion: (A) A schematic illustration of direct extrusion bioprinting process; (B1-B2) an image of printed 2\% xanthan gum (XG)-alginate gum tubular structures (reproduced/adapted with permission from Ref. [83]); (C1) a photograph of bioprinted alginate (black) in a gelatin support bath and (C2) a time-lapsed image of arterial tree when a black dye was perfused through the system in 6 seconds time frame (reproduced/adapted with permission from Ref. [84]).

Fig. 3. Coaxial bioprinting: (A) A schematic illustration of vascular like structures of the coaxial extrusion process; (B1) an image of bioprinted alginate microfluidic channels, (B2) where cell viability of $62.5 \pm 0.05 \%$ was achieved after $12 \mathrm{~h}$ of media perfusion(reproduced/adapted with permission from Ref. [88]); (C1) an image of MWBTs-reinforced alginate vascular conduits (C2) with cell viability was around $70 \%$ after three days culture (reproduced/adapted with permission from Ref. [92]); (D1) a photograph of bioprinted hollow filaments with $2 \%$ alginate solutions, (D2 - D3) where the average inner diameter was $892 \mu \mathrm{m}$ and the average outer diameter was $1,192 \mu \mathrm{m}$. Cell culture medium was perfused though the channel without any occlusionissue (reproduced/adapted with permission from Ref. [93]); (E1) a schematic of a gel construct with embedded hollow tubes, (E2) with a thickness from $800 \mu \mathrm{m}$ to $2.5 \mathrm{~mm}$ (reproduced/adapted with permission from Ref. [94]). 
Fig. 4. Indirect extrusion: A step-by-step illustration of bioprinting of a perfusable chip including (A1) step 1: a device is prepared with a cover slide on the bottom for microcopy purposes, (A2) step 2: bioprinting of a matrix material into the device, (A3) step 3: bioprinting of a fugitive ink for temporary support, (A4) step 4: bioprinting the matrix material to fill the device and liquefying the fugitive ink; (B1) an image showing bifurcating agarose template fibers and (B2) a photograph of the printed agarose filaments depicting respective network in GelMA hydrogel (reproduced/adapted with permission from Ref. [98]); (C1) a florescence microscope image of bifurcating micro-channels inside GelMA construct, (C2) an image showing CD31 (green) and nuclei (blue) staining of HUVECs (reproduced/adapted with permission from Ref. [99]; (D1) a schematic of a 3D perfusable chip, (D2 - D3) where the fluorescence images depict long-term culture of HUVEC-lined (red) with HNDF-laden support (green) at 45 days of perfusion (reproduced/adapted with permission from Ref. [170]).

Fig. 5. Droplet-based bioprinting for vascular tissue biofabrication: (A) a schematic illustration of DBB, where loaded bioink is dispensed and the bioink jet breaks into small droplets; (B) inkjet bioprinting of alginate into a $\mathrm{CaCl}_{2}$ solution enabled fabrication of and horizontal tube with predictive compensation step-by-step (reproduced/adapted with permission from Ref. [111]; (C) computed tomography (CT) images (left, middle) of the submerged constructs with $5 \mathrm{~mm}$ in outer diameter and $3 \mathrm{~cm}$ in length (right) (reproduced/adapted with permission from Ref. [124]); (D1) a fluorescent image of HUVECs (red) seeded into a printed channel, (D2) laminar flow in the channel was represented by green fluorescent beads, (D3) a combined image of green fluorescent beads and seeded HUVECs (reproduced/adapted with permission from Ref. [130]); (E) fluorescent images of vascular channels in fibrin gel with capillary network in between (from Day 2 to 14), where GFP-transfected HUVECs were embedded within fibrin and RFPtransfected HUVECs were lined in channels (reproduced/adapted with permission from Ref. [21]).

Fig. 6. Laser-based bioprinting of vascular constructs: (A) A schematic illustration of processes based on cell transfer; (B) a schematic illustration of typical photolithography involved processes; (C1) images of bioprinted fibroblast tubes made of $2 \%$ alginate loaded with $5 \times 10^{6}$ cells/ml and (C2) different views of Y-shaped alginate tubes bioprinted using 8\% sodium alginate solution (reproduced/adapted with permission from Ref. [145]); (D) direct cell 
patterning in collagen hydrogels using a near-infrared femtosecond laser, where confocal microscopy images show tube formation in 14 days (reproduced/adapted with permission from Ref. [149]); (E) scanning electron microscopy images showing a complex vascular network in PEGDA hydrogel (reproduced/adapted with permission from Ref. [150]).

Fig. 7. Scaffold-free bioprinting for vascular tissue fabrication: (A1-A5) A schematic illustration showing scaffold-free vascular tissue bioprinting step by step, where agarose rods (pink) and uniform multicellular spheroids (orange) were deposited layer-by-layer (reproduced/ adapted with permission from Ref. [163]); (B1) maturation of bioprinted tubes composed of porcine aortic smooth muscle cells (PASMCs), (B2) scaffold-free bioprinting of a bifurcated vascular network using human skin fibroblast (HSF) spheroids, (B3) where spheroids fuse and mature into tissue in 6 days(reproduced/ adapted with permission from Ref. [163]); (C1-C2) bioprinting alginate mold to hold vascular spheroids, (C3) which facilitates tissue formation in three days (C4) followed by further proliferation of cells in 16 days(reproduced/adapted with permission from Ref. [161]). 


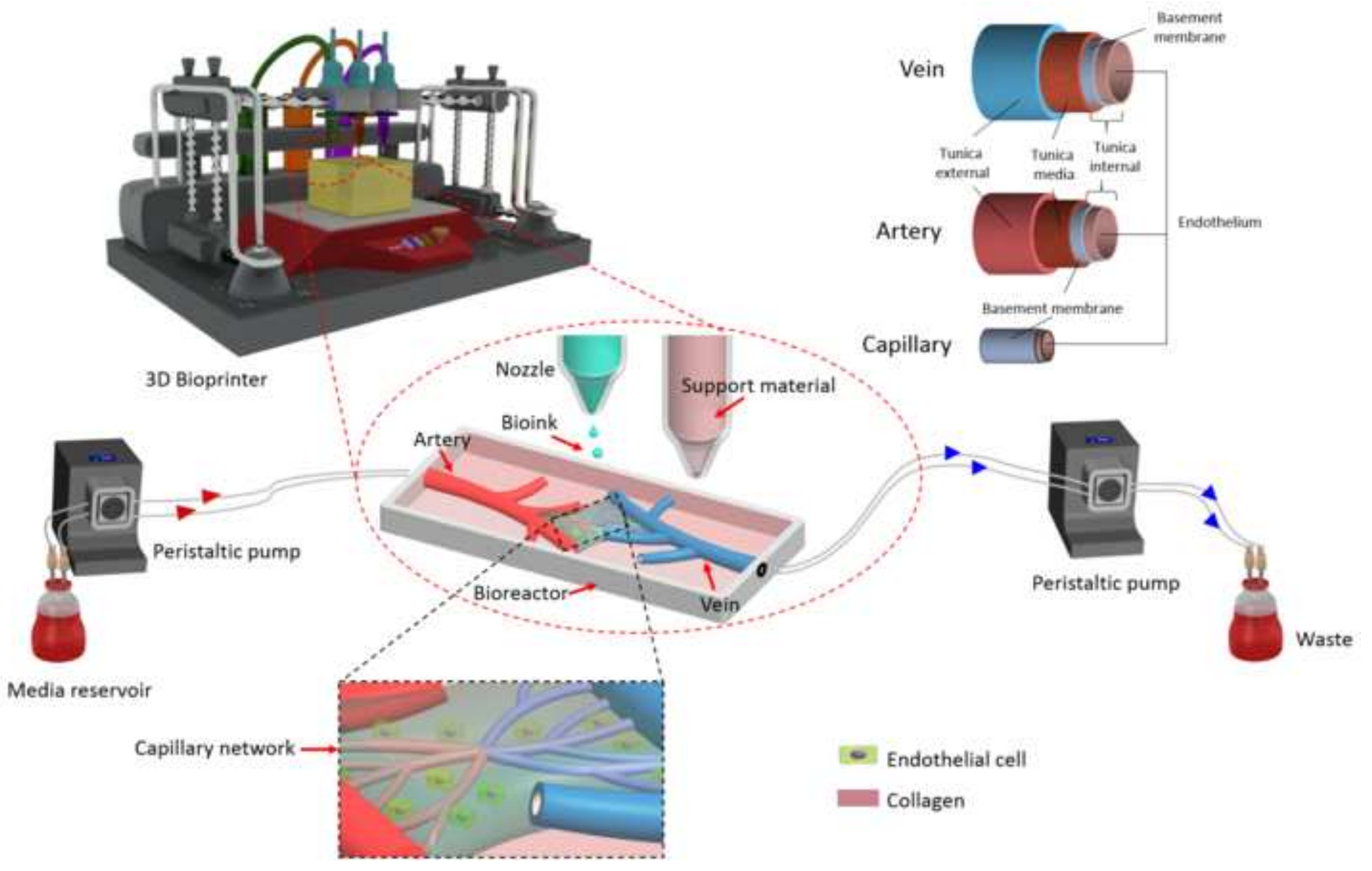

3D Bioprinter

oir
- Endothelial cell

Collagen 

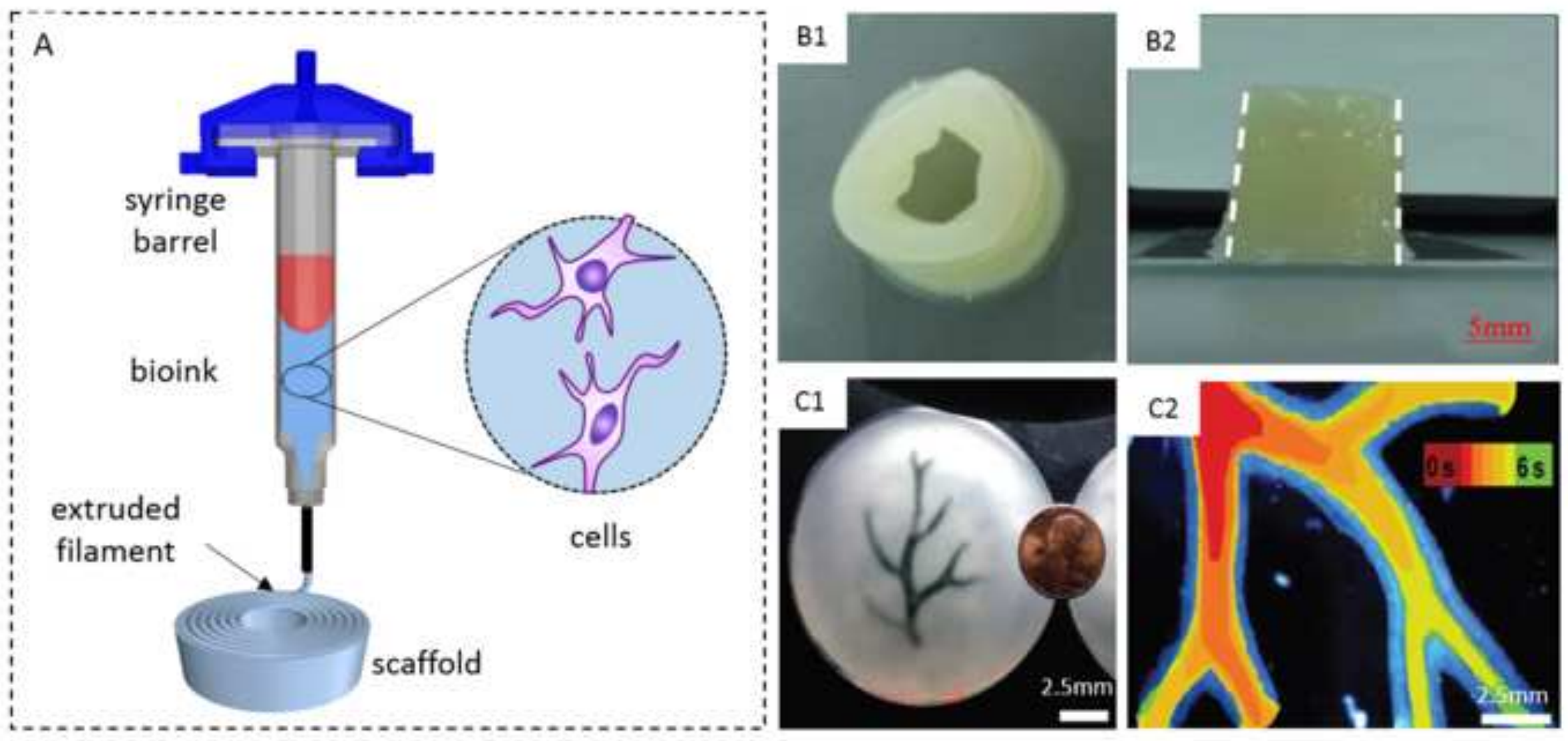

\section{B2}
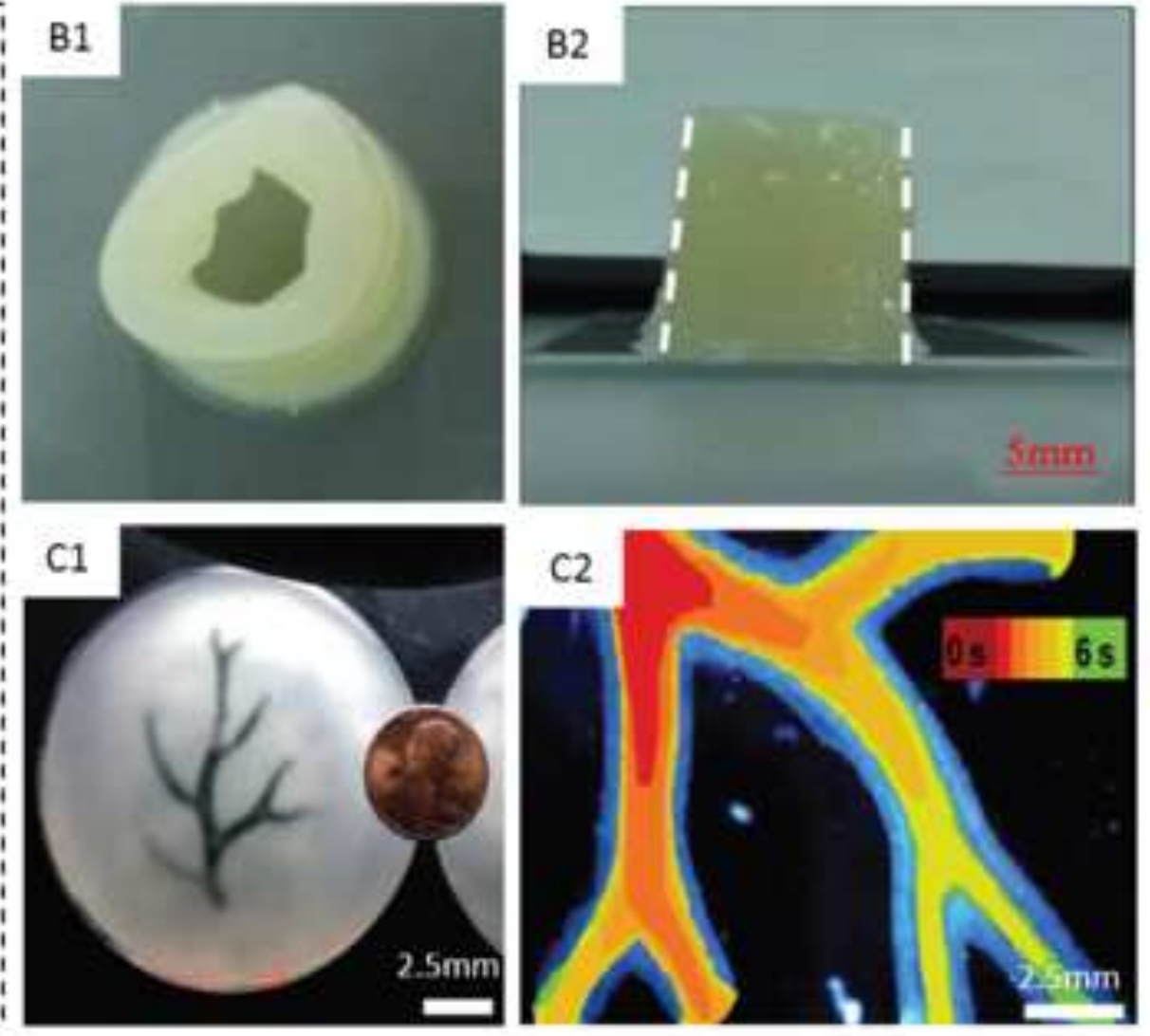

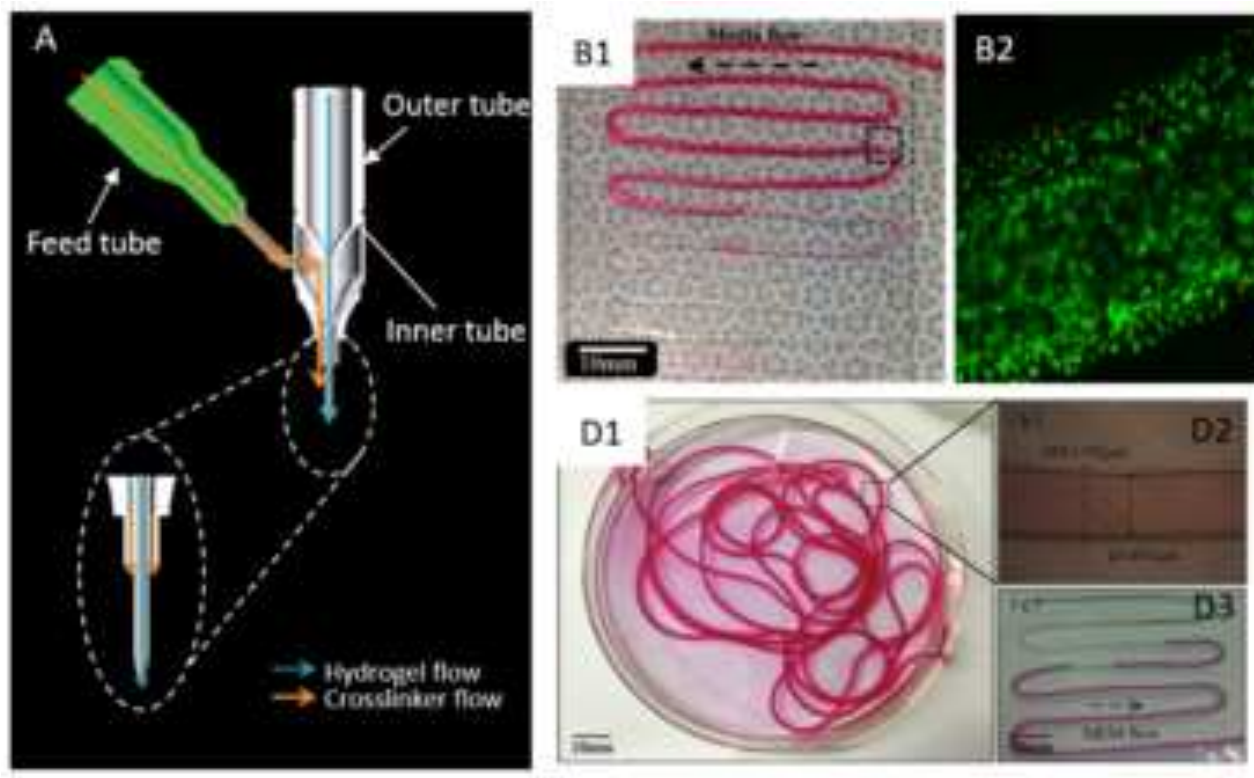

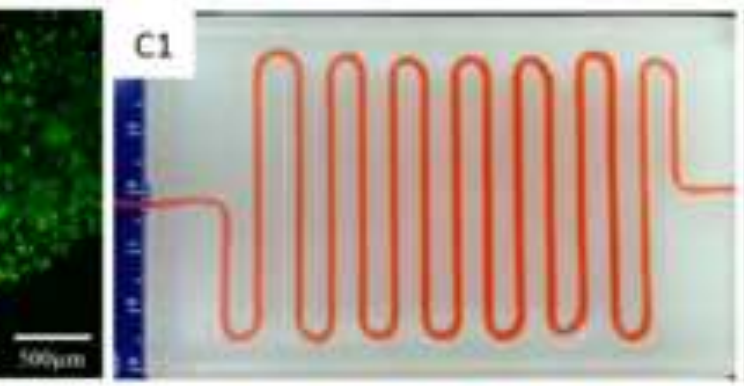

EI

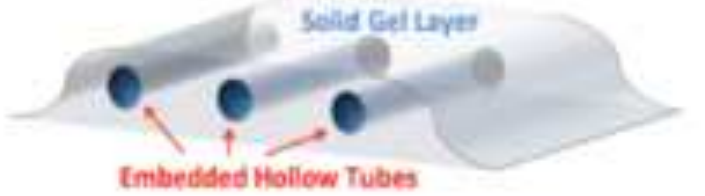

C2

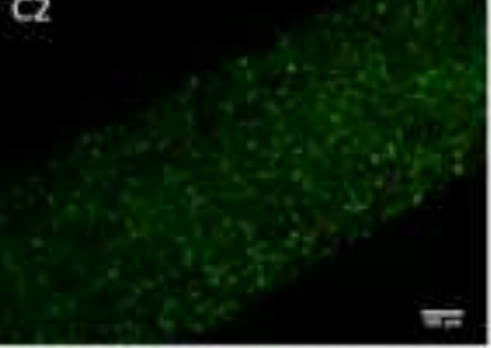

E2

Hollow Tube

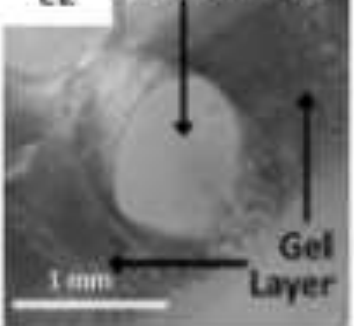



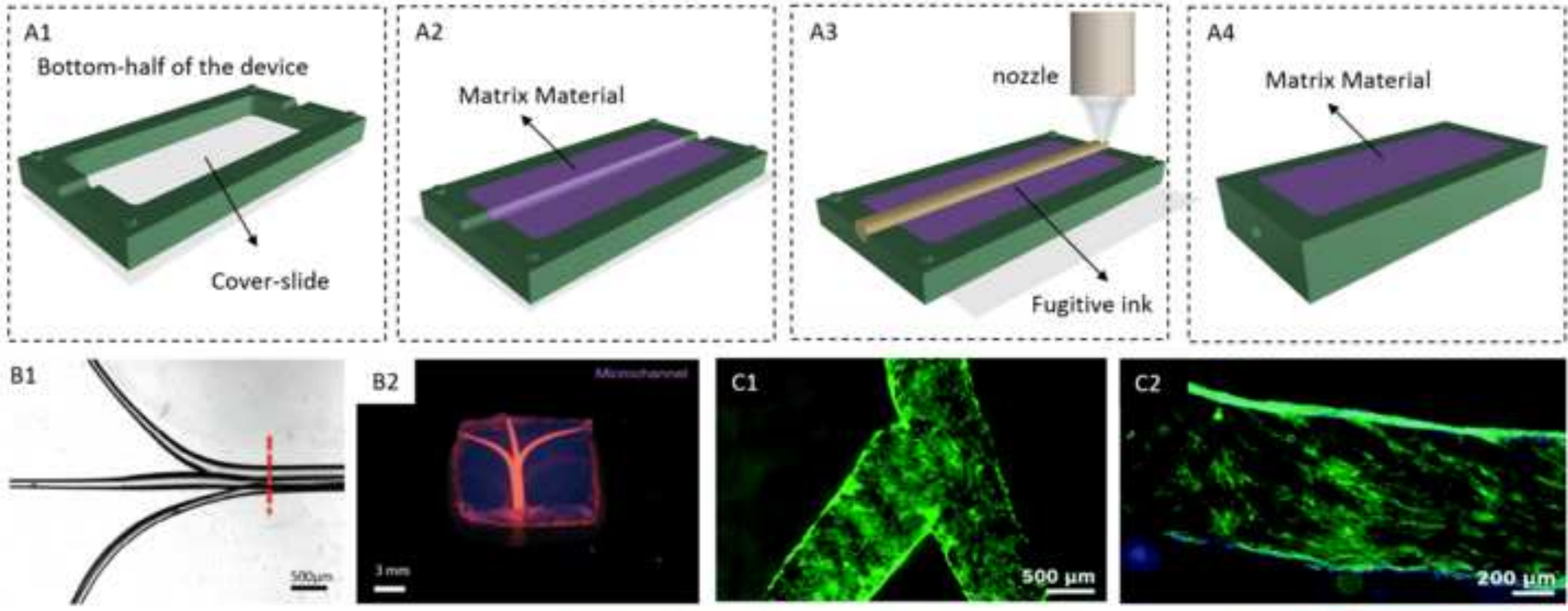

D1

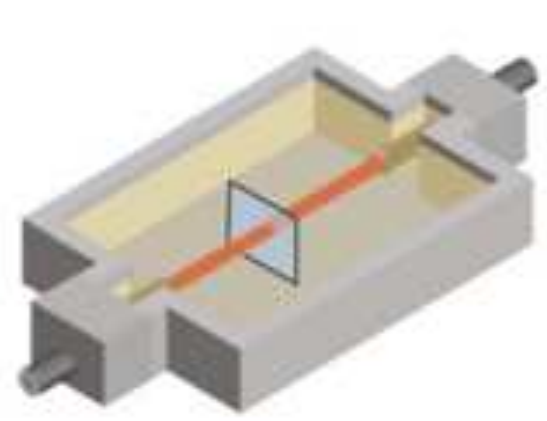

D2

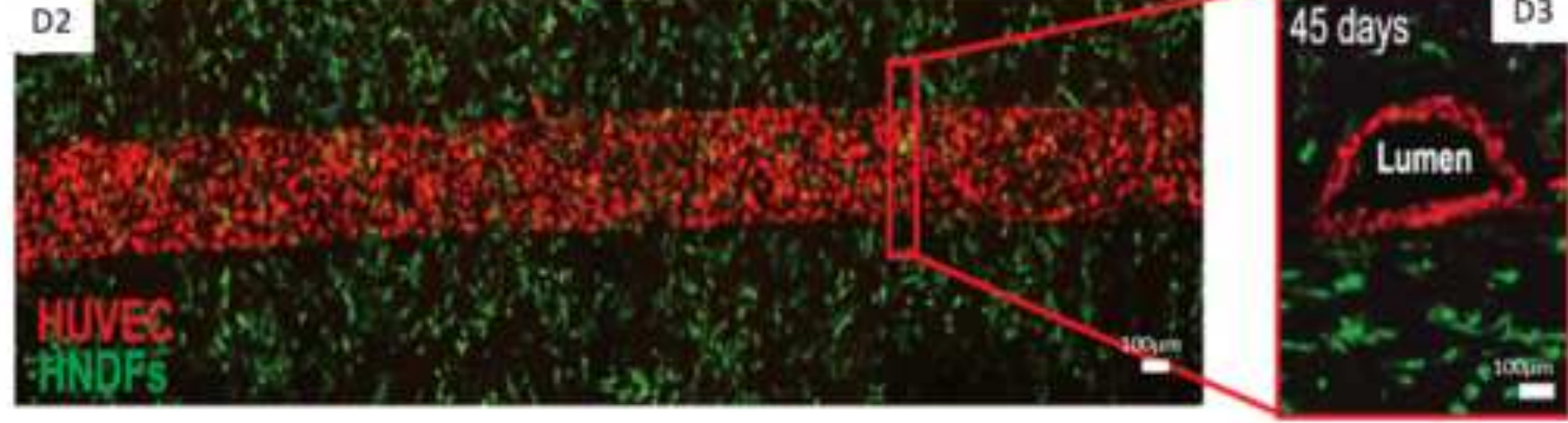




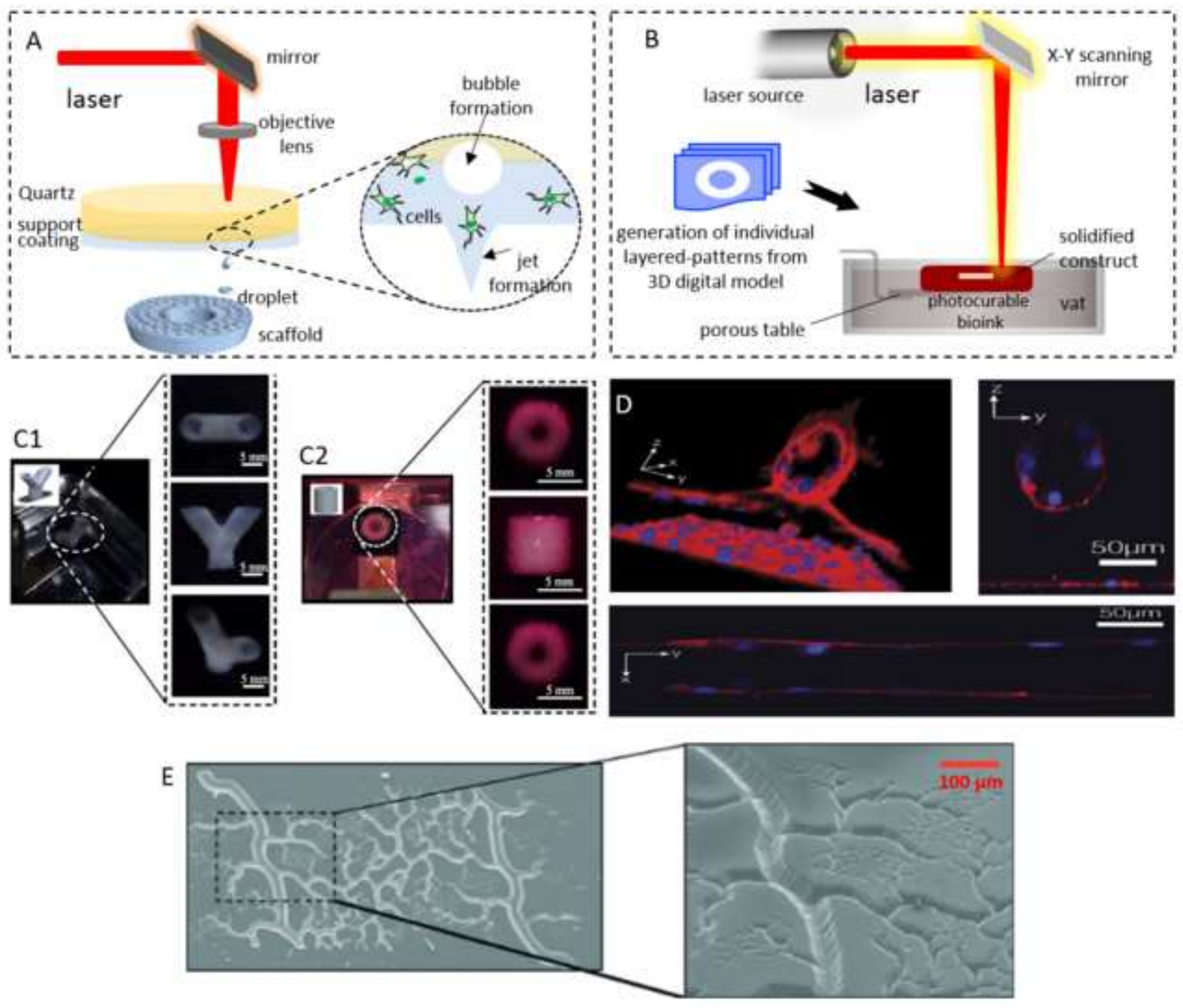


A1

A2

A3

A4
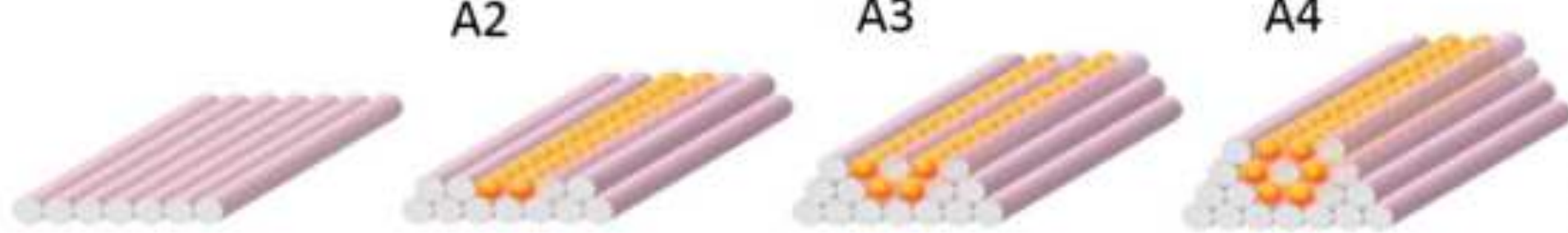

A5

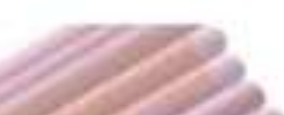

B1
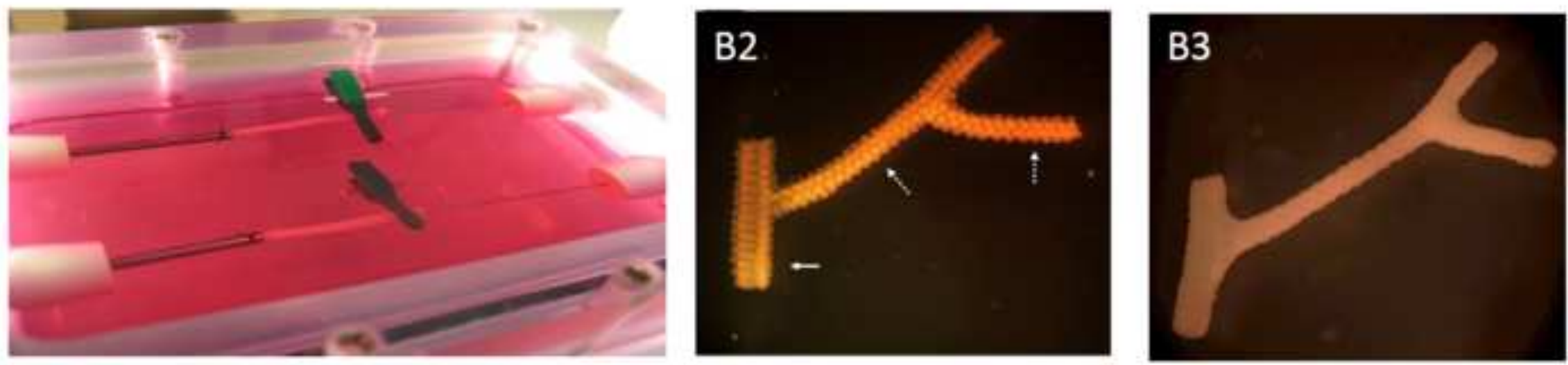

C1
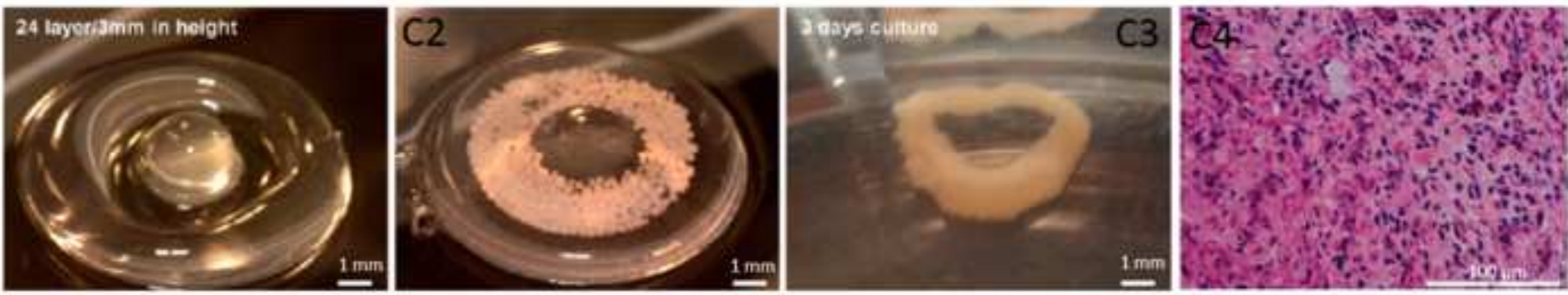


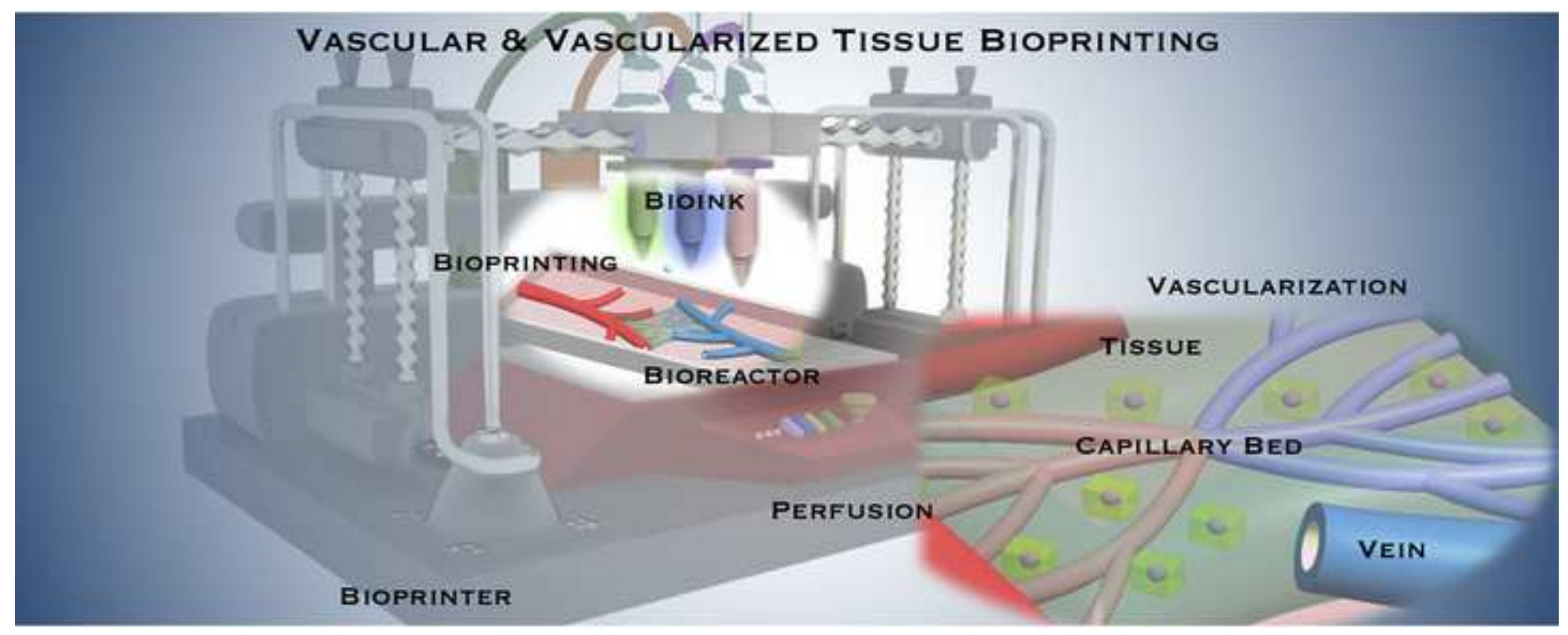

